\title{
Design and characterization of genetically engineered zebrafish aquaporin-3 mutants highly permeable to the cryoprotectant ethylene glycol
}

\author{
François Chauvigné ${ }^{1}$ Esther Lubzens ${ }^{2}$ and Joan Cerdà ${ }^{*}$
}

\begin{abstract}
Background: Increasing cell membrane permeability to water and cryoprotectants is critical for the successful cryopreservation of cells with large volumes. Artificial expression of water-selective aquaporins or aquaglyceroporins (GLPS), such as mammalian aquaporin-3 (AQP3), enhances cell permeability to water and cryoprotectants, but it is known that AQP3-mediated water and solute permeation is limited and $\mathrm{pH}$ dependent. To exploit further the possibilities of using aquaporins in cryobiology, we investigated the functional properties of zebrafish (Danio rerio) GLPs.

Results: Water, glycerol, propylene glycol and ethylene glycol permeability of zebrafish Aqp3a, -3b, -7, -9a, -9b, $-10 \mathrm{a}$ and $-10 \mathrm{~b}$, and human AQP3, was examined. Expression in Xenopus laevis oocytes indicated that the permeability of DrAqp3a and -3b to ethylene glycol was higher than for glycerol or propylene glycol under isotonic conditions, unlike other zebrafish GLPs and human AQP3, which were more permeable to glycerol. In addition, dose-response experiments and radiolabeled ethylene glycol uptake assays suggested that oocytes expressing DrAqp3b were permeated by this cryoprotectant more efficiently than those expressing AQP3. Water and ethylene glycol transport through DrAqp3a and -3b were, however, highest at pH 8.5 and completely abolished at pH 6.0. Point mutations in the DrAqp3b amino acid sequence rendered two constructs, DrAqp3bT85A showing higher water and ethylene glycol permeability at neutral and alkaline $\mathrm{pH}$, and DrAqp3b-H53A/G54H/ T85A, no longer inhibited at acidic pH but less permeable than the wild type. Finally, calculation of permeability coefficients for ethylene glycol under concentration gradients confirmed that the two DrAqp3b mutants were more permeable than wild-type DrAqp3b and/or AQP3 at neutral pH, resulting in a 2.6- to 4-fold increase in the oocyte intracellular concentration of ethylene glycol.

Conclusion: By single or triple point mutations in the DrAqp3b amino acid sequence, we constructed one mutant with enhanced ethylene glycol permeability and another with reduced $\mathrm{pH}$ sensitivity. The DrAqp3b and the two mutant constructs may be useful for application in cryobiology.
\end{abstract}

\section{Background}

Over the last decades, advances in understanding basic phenomena in cryobiology has led the development of effective methods for the preservation of a very wide range of cells [1]. However, the cryopreservation of cells with large volumes and multicellular systems and tissues, such as vertebrate oocytes and embryos, still remains a challenge in some cases [2-4]. Vertebrate

\footnotetext{
* Correspondence: joan.cerda@irta.es

'Laboratory of Institut de Recerca i Tecnologia Agroalimentàries (IRTA)Institut de Ciències del Mar, Consejo Superior de Investigaciones Científicas (CSIC), 08003 Barcelona, Spain

Full list of author information is available at the end of the article
}

oocytes show low surface area to volume ratio and low permeability to water and cryoprotectants, and as a consequence they are highly susceptible to formation of intracellular ice, cryoprotectant-toxicity, and osmotic stress. In addition, oocyte cryosurvival may change during development or as a result of different genotypes $[4,5]$.

One of the major obstacles with freezing of a cell is that intracellular water content crystallizes, leading to mechanical and physical damage [6,7]. To limit the rate of ice crystals formation, the first step is to permeate cells with cryoprotectant agents, such as glycerol, propylene glycol, dimethyl sulfoxide or ethylene glycol, which

\section{Biomed Central}


should reach high intracellular concentrations, thus generating the driving force for the efflux of water by osmosis and of solutes by diffusion [6,7]. This can be achieved either by a slow cooling rates with low concentration of cryoprotectants, or fast cooling after incubation in highly concentrated cryoprotectant solutions (vitrification) [8,9]. An ideal cryoprotectant should thus exhibit low toxicity and rapidly permeate the cell, so that osmotic volume changes, that are a recognized form of cellular stress, are minimized [10-12]. Ethylene glycol shows the best efficiency/toxicity ratio on mammalian oocytes and embryos and is thus the most common selected cryoprotectant for slow-cooling or vitrification protocols [13-18]. However, the permeability of vertebrate oocytes and embryos to ethylene glycol is limited [19-24] and may change during development and differentiation $[3,4]$, resulting possibly in intracellular damage after cryopreservation $[4,16,25]$.

It is now well established that biological membranes allow water to pass by simple diffusion through the lipid bilayer, or when rapid water permeability is required (in case of reabsorption, secretion or osmotic stress), through specialized membrane channels known as aquaporins. Aquaporins (AQPs) are integral membrane proteins present in all living organisms from bacteria to mammals [26]. These proteins consist of six transmembrane helices connected by five loops, two of which bear the highly conserved asparagine-proline-alanine (NPA) motifs involved in the formation of the water pore [26]. To date, 13 aquaporins have been identified in mammals (AQP0-12) and while most of them are waterselective, functional studies have identified a subgroup of channels (AQP3, -7, -9 and -10) that can transport also glycerol and urea, and are termed aquaglyceroporins (GLPs) [26,27]. Some GLPs are also permeated by metalloids and a wide variety of noncharged solutes (e. g., carbamides, polyols, purines, pyrimidines), including cryoprotectants such as propylene glycol, ethylene glycol, acetamide and possibly dimethyl sulfoxide [28-32].

The discovery of aquaporins made it possible to use them for enhancing water and cryoprotectant permeability of cells [33-35]. In the baker's yeast (Saccharomyces cerevisiae), freeze tolerance during rapid freezing conditions positively correlates with high levels of expression of the water-selective aquaporins Aqy1 and Aqy2 $[33,36]$. This positive effect has been explained by the rapid water efflux, especially at freezing temperatures, as a consequence of high levels of aquaporins in the plasma membrane of yeast cells, resulting in the reduction of intracellular ice crystal formation and cell damage. Similarly, heterologous expression of wild-type (WT) mammalian aquaporin-3 (AQP3) in vertebrate oocytes and embryos enhances both the efflux of water and influx of cryoprotectants into the cells [31,34,35,37-41]. In the case of mouse oocytes, this method ameliorates oocyte tolerance to freezing and survival after thawing [35].

The increased permeability mediated by the artificial expression of AQP3 may be however insufficient for cryosurvival of cells or multicellular systems with large volumes, such as oocytes and embryos from lower vertebrates [39]. This may be related to a decreased translation efficiency of AQP3 when expressed in an heterologous system and/or a limited water and solute permeability of AQP3 $[39,42,43]$. In addition, AQP3 is $\mathrm{pH}$-dependant [44], and therefore, an effect of $\mathrm{pH}$ on AQP3-mediated water and cryoprotectant transport is likely to occur. This additional obstacle should be considered when using AQP3 in cryobiology as the intracellular $\mathrm{pH}$ is altered during volumetric changes in cells exposed to hypertonic or hypotonic environments [45-47]. Furthermore, the intracellular $\mathrm{pH}$ can be affected by the presence of cryoprotectants within the cell as some of them are dipolar aprotic or protic solvents and act as hydrogen bond acceptors or proton donors, and affect the acid-base equilibrium in mixed solvent systems [46]. Therefore, exploiting further the possibilities of using aquaporins in cryobiology, it would be useful to develop aquaporins with enhanced permeability or $\mathrm{pH}$ insensitivity, by investigating GLPs of nonmammalian origin that may be more permeable to water and cryoprotectants than mammalian AQP3.

Recently, we have characterized the genomic repertoire of zebrafish (Danio rerio) aquaporins which contains seven GLP isoforms: DrAqp3a and -3b, DrAqp7, DrAqp9a and -9b, and DrAqp10a and -10b [48]. Functional expression in Xenopus laevis oocytes demonstrated that all the zebrafish GLPs transport water, glycerol and urea in a similar manner as the mammalian orthologs [48], and therefore these channel proteins are of potential interest for cryobiology. In the present study, we have investigated both the $\mathrm{pH}$ sensitivity and cryoprotectant permeability of the zebrafish GLPs by using the $X$. laevis oocyte expression system. Interestingly, we found that both DrAqp3a and -3b isoforms are much more permeable to ethylene glycol than to glycerol or propylene glycol at neutral or alkaline $\mathrm{pH}$, while all other zebrafish GLPs, as well as human AQP3, are more permeable to glycerol. Since ethylene glycol is a suitable cryoprotectant, we further engineered two DrAqp3 mutants that were insensitive to changes in $\mathrm{pH}$ or exhibit enhanced ethylene glycol permeability.

\section{Results}

Effect of pH on water and cryoprotectant permeability of zebrafish GLPs and human AQP3

The effect of external $\mathrm{pH}$ on water permeability of $X$. laevis oocytes injected with capped RNA (cRNA) encoding DrAqp3a -3b, -7, -9a, -9b, -10a, or $-10 b$ was 
determined by measuring the rate of swelling in hypotonic modified Barth's medium (MBS) (Figure 1). For comparison, oocytes were injected with DrAqp1a or human AQP3 (HsAQP3). The $\mathrm{pH}$ of the incubation medium affected the osmotic water permeability $\left(P_{\mathrm{f}}\right)$ of oocytes expressing HsAQP3, DrAqp3a, -3b, -7, and -10b, whereas the $P_{\mathrm{f}}$ of oocytes injected with DrAqp1a, $-9 \mathrm{a},-9 \mathrm{~b}$, and $-10 \mathrm{a}$ did not changed significantly within the range of $\mathrm{pH}$ tested. However, the effect of $\mathrm{pH}$ on oocyte $P_{\mathrm{f}}$ relied on the specific expressed aquaporin. Thus, the $P_{\mathrm{f}}$ of oocytes expressing DrAqp7 was inhibited by approximately $50 \%$ at $\mathrm{pH} 6$, whereas the DrAqp $10 \mathrm{~b}$ oocytes, exhibiting very low water permeability at $\mathrm{pH} 6$ and 7.5 (approximately 1.5-fold increase in both cases with respect the control oocytes), showed an enhanced $P_{\mathrm{f}}$ at pH.8.5 (2.5-fold increase). For oocytes expressing HsAQP3 or zebrafish AQP3 isoforms, the $P_{\mathrm{f}}$ was inhibited at acidic $\mathrm{pH}$ but in a different manner. The $P_{\mathrm{f}}$ of HsAQP3 oocytes was only partially inhibited (by approximately $55 \%$ ) at $\mathrm{pH} 6$, whereas it remained similar at neutral and basic $\mathrm{pH}$, as it has been described previously [44]. In contrast, the $P_{\mathrm{f}}$ of DrAqp3a and $-3 \mathrm{~b}$ oocytes was completely abolished at $\mathrm{pH} 6$, and was higher at basic than at neutral pH. Thus, in DrAqp3a oocytes the $P_{\mathrm{f}}$ increased by 5 - and 10 -fold with respect the control oocytes at $\mathrm{pH} 7.5$ and 8.5 , respectively, whereas the $P_{\mathrm{f}}$ of DrAqp3b oocytes increased by 2.5 and 11 -fold at $\mathrm{pH} 7.5$ and 8.5 , respectively. It thus appears that human AQP3 and the zebrafish orthologs exhibit different sensitivity to $\mathrm{pH}$.

The permeability of $X$. laevis oocytes expressing HsAQP3 or zebrafish GLPs to the cryoprotectants glycerol, propylene glycol and ethylene glycol $\left(P_{\mathrm{Gly}}, P_{\mathrm{PG}}\right.$ and $P_{\mathrm{EG}}$, respectively) at different $\mathrm{pH}$ was determined volumetrically. In these experiments, control and aquaporin-expressing oocytes were exposed to isotonic solutions containing $160 \mathrm{mM}$ of the respective solutes and changes in oocyte volume were recorded during $1 \mathrm{~min}$. In general, the solute permeability $\left(P_{\mathrm{S}}\right)$ of control oocytes and of oocytes expressing the different GLPs was affected by changes in $\mathrm{pH}$ (Table 1). Calculation of the oocyte $P_{\mathrm{S}}$ as fold increase with respect that of the controls revealed that the $\mathrm{pH}$ changed the $P_{\mathrm{S}}$ in a manner similar to the $P_{\mathrm{f}}$, except for oocytes expressing HsAQP3 which $P_{\mathrm{EG}}$ remained unchanged regardless of the $\mathrm{pH}$ of the medium (Table 1). Oocytes expressing DrAqp7, -9a, -9b, -10a and -10b, or HsAQP3, were significantly $(p<0.05)$ more permeable to glycerol than propylene glycol or ethylene glycol at pH 7.5 (Table 1). In contrast, DrAqp3a or -3b oocytes exhibited significantly $(p<0.05)$ higher permeability to ethylene glycol than to the other cryoprotectants at $\mathrm{pH} 7.5$ or 8.5. At $\mathrm{pH} 8.5$, the $P_{\mathrm{EG}}$ of DrAqp3b oocytes was greatly enhanced resulting in bursting of the oocytes. To

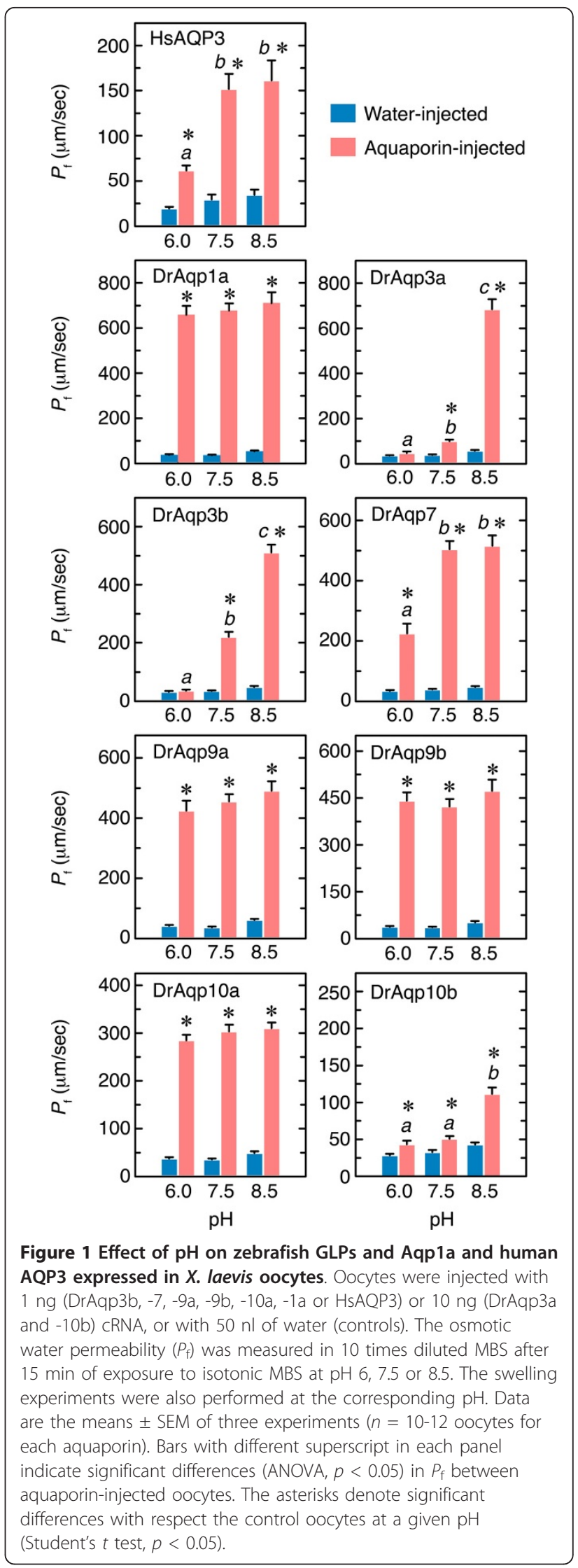


Table 1 Cryoprotectant permeability $\left(P_{S}\right)$ of $X$. laevis oocytes expressing human AQP3 or zebrafish GLPs in isotonic solutions at different $\mathrm{pH}$ containing $160 \mathrm{mM}$ of solutes

\begin{tabular}{|c|c|c|c|c|c|c|c|c|c|}
\hline & \multicolumn{3}{|c|}{$P_{\text {Gly }}\left(\times 10^{-3} \mathrm{~cm} / \mathrm{min}\right)$} & \multicolumn{3}{|c|}{$P_{\mathrm{PG}}\left(\times 10^{-3} \mathrm{~cm} / \mathrm{min}\right)$} & \multicolumn{3}{|c|}{$P_{\mathrm{EG}}\left(\mathrm{x} 10^{-3} \mathrm{~cm} / \mathrm{min}\right)$} \\
\hline & $\mathrm{pH} 6.0$ & $\mathrm{pH} 7.5$ & $\mathrm{pH} 8.5$ & $\mathrm{pH} 6.0$ & $\mathrm{pH} 7.5$ & $\mathrm{pH} 8.5$ & $\mathrm{pH} 6.0$ & $\mathrm{pH} 7.5$ & $\mathrm{pH} 8.5$ \\
\hline HsAQP3 & $\begin{array}{l}9.95 \pm 1.17^{a} \\
(1.64 \pm 0.29)\end{array}$ & $\begin{array}{c}35.22 \pm 3.48^{c} \\
(2.07 \pm 0.32)\end{array}$ & $\begin{array}{c}49.62 \pm 5.96^{\mathrm{e}} \\
(3.13 \pm 0.38)\end{array}$ & $\begin{array}{l}10.05 \pm 1.64^{a} \\
(2.47 \pm 0.29)\end{array}$ & $\begin{array}{c}28.93 \pm 3.62^{c} \\
(3.13 \pm 0.34)\end{array}$ & $\begin{array}{c}38.14 \pm 2.87^{c d} \\
(5.23 \pm 0.56)\end{array}$ & $\begin{array}{l}18.34 \pm 2.32^{b} \\
(1.97 \pm 0.31)\end{array}$ & $\begin{array}{l}32.38 \pm 2.87^{c} \\
(4.30 \pm 0.40)\end{array}$ & $\begin{array}{l}36.53 \pm 3.28^{c} \\
(4.89 \pm 0.62)\end{array}$ \\
\hline DrAqp3a & $\begin{array}{l}2.21 \pm 0.40^{a} \\
(1.45 \pm 0.20)\end{array}$ & $\begin{array}{l}4.64 \pm 0.97^{b} \\
(2.10 \pm 0.30)\end{array}$ & $\begin{array}{c}32.64 \pm 4.53^{\mathrm{d}} \\
(3.33 \pm 0.48)\end{array}$ & $\begin{array}{l}5.73 \pm 0.91^{b} \\
(2.41 \pm 0.21\end{array}$ & $\begin{array}{l}16.09 \pm 1.86^{c} \\
(2.64 \pm 0.28)\end{array}$ & $\begin{array}{r}71.08 \pm 6.85^{\mathrm{e}} \\
(5.41 \pm 0.46)\end{array}$ & $\begin{array}{l}3.76 \pm 0.69^{a b} \\
(1.83 \pm 0.29)\end{array}$ & $\begin{array}{c}20.63 \pm 3.18^{c} \\
(3.70 \pm 0.66)\end{array}$ & $\begin{array}{l}90.04 \pm 6.02^{f} \\
(3.77 \pm 0.39)\end{array}$ \\
\hline DrAqp3b ${ }^{1}$ & $\begin{array}{l}1.71 \pm 0.43^{\mathrm{a}} \\
(1.11 \pm 0.25)\end{array}$ & $\begin{array}{c}12.81 \pm 1.24^{b} \\
(1.47 \pm 0.31)\end{array}$ & $\begin{array}{c}57.37 \pm 3.03^{d} \\
(2.93 \pm 0.63)\end{array}$ & $\begin{array}{l}1.92 \pm 0.42^{\mathrm{a}} \\
(1.54 \pm 0.33)\end{array}$ & $\begin{array}{c}28.27 \pm 2.51^{c} \\
(3.77 \pm 0.37)\end{array}$ & $\begin{array}{r}70.08 \pm 4.48^{\mathrm{e}} \\
(7.84 \pm 0.98)\end{array}$ & $\begin{array}{l}1.46 \pm 0.29^{\mathrm{a}} \\
(1.15 \pm 0.71)\end{array}$ & $\begin{array}{r}79.22 \pm 5.70^{e} \\
(4.50 \pm 0.50)\end{array}$ & - \\
\hline DrAqp7 & nd & $\begin{array}{r}97.99 \pm 7.16^{c} \\
(3.85 \pm 0.55)\end{array}$ & nd & nd & $\begin{array}{c}40.76 \pm 3.37^{a} \\
(3.34 \pm 0.35)\end{array}$ & nd & $\mathrm{Nd}$ & $\begin{array}{c}50.55 \pm 2.81^{b} \\
(4.53 \pm 0.57)\end{array}$ & nd \\
\hline DrAqp9a & nd & $\begin{array}{c}27.58 \pm 1.85^{a} \\
(1.76 \pm 0.16)\end{array}$ & nd & nd & $\begin{array}{r}29.40 \pm 3.19^{a} \\
(5.06 \pm 0.37)\end{array}$ & nd & $\mathrm{Nd}$ & $\begin{array}{c}61.62 \pm 4.45^{b} \\
(7.75 \pm 0.60)\end{array}$ & nd \\
\hline DrAqp9b & nd & $\begin{array}{c}52.48 \pm 3.54^{b} \\
(1.92 \pm 0.24)\end{array}$ & nd & nd & $\begin{array}{r}31.27 \pm 4.39^{a} \\
(3.94 \pm 0.38)\end{array}$ & nd & $\mathrm{Nd}$ & $\begin{array}{c}56.03 \pm 4.30^{b} \\
(9.24 \pm 0.70)\end{array}$ & nd \\
\hline DrAqp10a & nd & $\begin{array}{c}31.05 \pm 3.01^{b} \\
(1.60 \pm 0.23)\end{array}$ & nd & nd & $\begin{array}{l}13.02 \pm 1.45^{\mathrm{a}} \\
(4.45 \pm 0.41)\end{array}$ & nd & $\mathrm{Nd}$ & $\begin{array}{l}19.14 \pm 1.17^{\mathrm{a}} \\
(6.99 \pm 0.61)\end{array}$ & nd \\
\hline DrAqp10b & $\begin{array}{l}1.15 \pm 0.16^{\mathrm{a}} \\
(1.29 \pm 0.21)\end{array}$ & $\begin{array}{l}2.29 \pm 0.32^{b} \\
(1.71 \pm 0.26)\end{array}$ & $\begin{array}{c}17.48 \pm 2.25^{\mathrm{ef}} \\
(2.84 \pm 0.52)\end{array}$ & $\begin{array}{l}2.45 \pm 0.50^{\mathrm{bc}} \\
(2.04 \pm 0.30)\end{array}$ & $\begin{array}{l}3.66 \pm 0.51^{c} \\
(2.59 \pm 0.30)\end{array}$ & $\begin{array}{l}13.21 \pm 1.35^{\mathrm{e}} \\
(4.59 \pm 0.56)\end{array}$ & $\begin{array}{l}3.30 \pm 0.99^{b c} \\
(1.93 \pm 0.30)\end{array}$ & $\begin{array}{l}6.70 \pm 0.82^{d} \\
(3.67 \pm 0.74)\end{array}$ & $\begin{array}{l}18.58 \pm 1.26^{f} \\
(3.77 \pm 0.41)\end{array}$ \\
\hline
\end{tabular}

Data are the means \pm SEM ( $n=10-12$ oocytes per treatment) of 3-4 experiments performed on different batches of oocytes. Due to natural variations in oocyte permeability between batches of oocytes, the $P_{\mathrm{S}}$ of water-injected oocytes (controls) is shown in parenthesis for each aquaporin. Oocytes were injected with 1 ng (DrAqp3b, $-7,-9 a,-9 b,-10 a,-1 a$, or HsAQP3) or $10 \mathrm{ng}$ (DrAqp3a and -10b) cRNA, or with $50 \mathrm{nl}$ of water. Data from the same row with different superscript are statistically significant (ANOVA, $p<0.05$ ). nd, not determined.

${ }^{1}$ No data available for $P_{\mathrm{EG}}$ at $\mathrm{pH} 8.5$ because DrAqp3b-expressing oocytes burst in $160 \mathrm{mM}$ ethylene glycol.

prevent this, oocytes were exposed to $100 \mathrm{mM}$ ethylene glycol instead of $160 \mathrm{mM}$, confirming the stimulatory effect of increasing $\mathrm{pH}$ on the $P_{\mathrm{EG}}$ of oocytes expressing DrAqp3b (data not shown).

In order to assure that the effect of $\mathrm{pH}$ on the $P_{\mathrm{f}}$ or $P_{\text {EG }}$ of DrAqp3b-expressing oocytes was not affected by the dilution of the ion concentrations in the MBS solution, oocytes were equilibrated in isotonic MBS containing sucrose, and a lower concentration of $\mathrm{NaCl}$, prior to the swelling assays (see Methods). These experiments confirmed that the $P_{\mathrm{f}}$ or $P_{\mathrm{EG}}$ at different $\mathrm{pH}$ of oocytes expressing DrAqp3b was identical regardless of the ion concentrations of the bathing solutions (Additional file 1 ), and therefore subsequent $P_{\mathrm{f}}$ assays were carried out in diluted MBS.

To further determine whether the ethylene glycol permeability of oocytes expressing DrAqp3b was higher than that of oocytes expressing HsAQP3, oocytes from the same batch were injected with increasing amounts of cRNA (1 to $40 \mathrm{ng}$ ) encoding HsAQP3 or DrAqp3b (Figure 2). Determination of the oocyte $P_{\mathrm{EG}}$ for each cRNA dose at $\mathrm{pH} 7.5$ showed that the $P_{\mathrm{EG}}$ of both HsAQP3- and DrAqp3b-injected oocytes reached a plateau with 20 ng cRNA, but the $P_{\mathrm{EG}}$ of DrAqp3b oocytes was significantly $(p<0.01)$ higher than that of the HsAQP3 oocytes at all tested cRNA doses (Figure 2A). Since the oocyte expression system was apparently saturated with the same cRNA dose in HsAQP3- and DrAqp3b-expressing oocytes, the differences in $P_{\mathrm{EG}}$ were likely not derived from differences in translation efficiency. To confirm that DrAqp3b-expressing oocytes permeated ethylene glycol more efficiently than those expressing HsAQP3, oocytes injected with $20 \mathrm{ng}$ DrAqp3b or HsAQP3 cRNA were exposed to radiolabeled ethylene glycol. These experiments showed that the uptake of isotope-labeled ethylene glycol by DrAqp3b oocytes was approximately $70 \%$ higher than in HsAQP3 oocytes (Figure 2B). Altogether, these results suggested that DrAqp3b was more permeable to ethylene glycol than to propylene glycol or glycerol, and that DrAqp3b oocytes permeated ethylene glycol more efficiently than those expressing HsAQP3.

Development of DrAqp3b mutants $\mathrm{pH}$ insensitive or with enhanced water and ethylene glycol permeability

The finding that both zebrafish Aqp3 isoforms were highly permeable to ethylene glycol prompted us to design Aqp3 mutant constructs that would be $\mathrm{pH}$ insensitive or show enhanced ethylene glycol permeability. The design of the mutants was based on the DrAqp3b deduced amino acid sequence (Figure 3 andTable 2) since the corresponding cRNA was expressed apparently more efficiently in $X$. laevis oocytes than that of DrAqp3a. To characterize the DrAqp3b-WT and mutants, their cRNAs were expressed in oocytes and the $P_{\mathrm{f}}$ monitored at different $\mathrm{pH}$ (Figure $4 \mathrm{~A}$ andAdditional file 2).

To design DrAqp3b constructs encoding aquaporins potentially $\mathrm{pH}$ insensitive, we targeted conserved residues that have been suggested to contribute to $\mathrm{pH}$ 


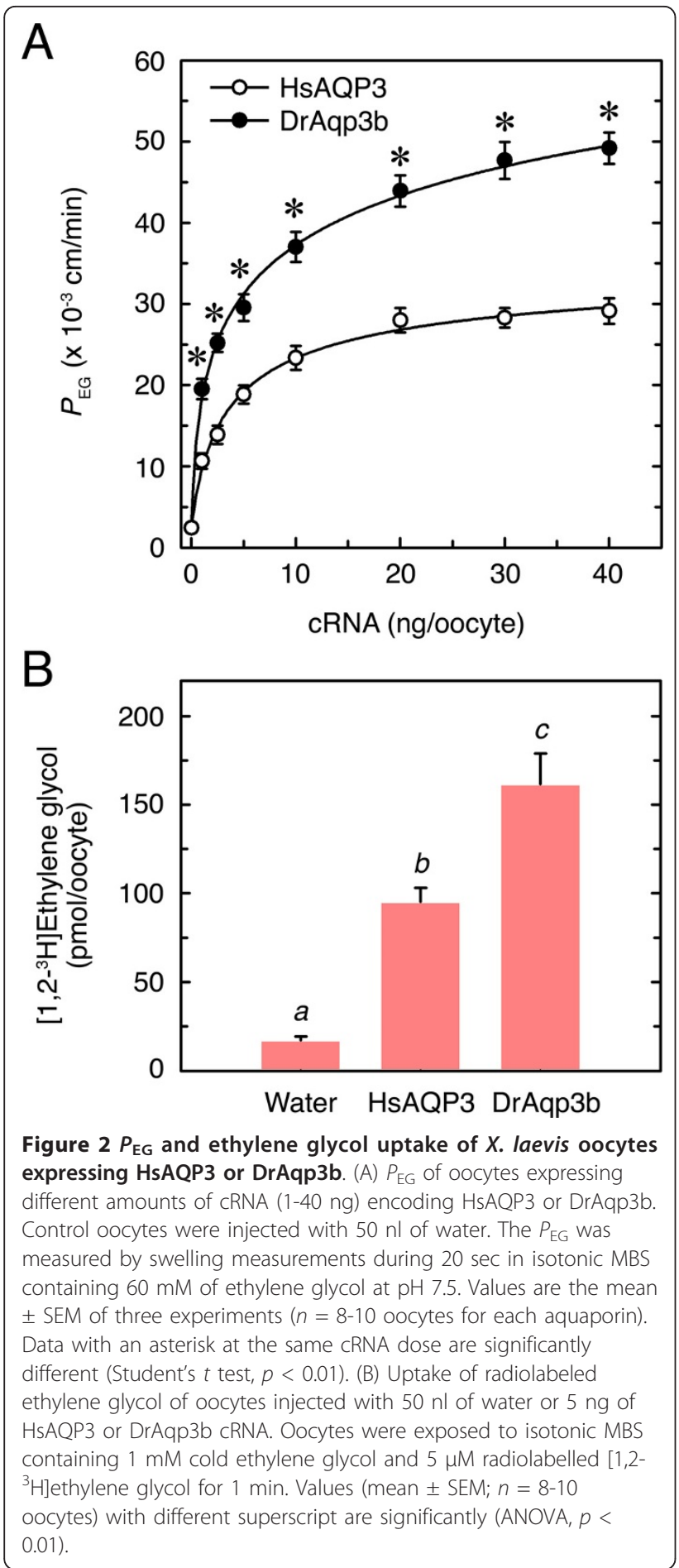

sensitivity in vertebrate and plant aquaporins, such as His, Arg, Glu and Tyr [49-53] (Table 2 and Figure 3). Within the external loop A, fish and human AQP3 contain a His residue $\left(\mathrm{His}^{53}\right.$ in DrAqp3b) that is conserved in killifish (Fundulus heteroclitus) Aqp0a ( $\mathrm{His}^{39}$ ) (Figure 3), which is, as AQP3, less permeable at acidic $\mathrm{pH}$ [51]. However, bovine (Bos taurus) AQP0, where the His in loop $\mathrm{A}$ is shifted one position $\left(\mathrm{His}^{40}\right)$ as compared to FhAqp0a (Figure 3), is more permeable at acidic $\mathrm{pH}$ [50]. Expression of DrAqp3b-H53A (Figure 4A) or -G54H (Additional file 2) in oocytes led to a global decrease in water permeability with respect DrAqp3bWT oocytes and did not affect $\mathrm{pH}$ sensitivity. By moving the His from position 53 to 54 (DrAqp3b-H53A/G54H), oocyte permeability at $\mathrm{pH} 6$ was increased by $97 \%(p<$ 0.05 ) with respect to DrAqp3b-WT oocytes. However, the permeability at $\mathrm{pH} 7.5$ and 8.5 of oocytes expressing this mutant was reduced when compared with DrAqp3b-WT oocytes (Figure 4A).

In the external loop $\mathrm{C}$, the $\mathrm{His}^{154}$ of DrAqp3b is conserved in FhAqp3a and HsAQP3 (Figure 3). This residue in HsAQP3 has been proposed to participate in the $\mathrm{pH}$ regulation of water permeability [49]. In DrAqp3b, His $^{154}$ was necessary for water permeability, since the $P_{\mathrm{f}}$ at $\mathrm{pH} 6$ and 7.5 of oocytes expressing DrAqp3b-H154A, -G54H/H154A, -H53A/H154A or -H53A/G54A/H154A, was strongly diminished with respect to that of the DrAqp3-WT oocytes, although it was slightly less inhibited at $\mathrm{pH} 8.5$ (Additional file 2).

Since Tyr residues have been reported to be implied in the pH sensitivity of HsAQP3 [49], and Arg residues may create electrostatic barriers that regulate aquaporin permeability [52], we also investigated the effect of mutations in these residues. The $\mathrm{Tyr}^{182}$ in the internal loop D of DrAqp3b is conserved in both fish and human AQP3 but not in other zebrafish GLPs and DrAqp1a (Figure 3). In addition, several Arg and Glu residues in the internal loop B ( $\mathrm{Arg}^{95}, \mathrm{Glu}^{96}$ and $\mathrm{Arg}^{99}$ in DrAqp3b) are highly conserved in vertebrate AQP3, of which $\mathrm{Arg}^{95}$ is retained in DrAqp7 and -10b that show decreased water permeability at $\mathrm{pH} 6$ (Figure 1). However, all the mutations performed at these sites (DrAqp3b-R95A, -E96A, -R99A, and-Y182A) did not affect significantly the $P_{\mathrm{f}}$ at any $\mathrm{pH}$ (Additional file 2), suggesting that these residues are not essential for water permeability or $\mathrm{pH}$ sensitivity in DrAqp3b.

The NPA motifs, together with the aromatic residue/ arginine $(\operatorname{ar} / \mathrm{R})$ constriction region (Figure 3), are believed to be involved in proton exclusion and channel selectivity of aquaporins [54,55]. Since DrAqp3b exhibits a particular feature within the first NPA box, apparently conserved in the Aqp3b of other teleosts [48], where the Ala residue is replaced by a Thr (Figure 3), we investigated whether the $\mathrm{Thr}^{85}$ of DrAqp3b can affect its permeability. The first NPT motif of DrAqp3b was mutated into NPA (DrAqp3b-T85A; Table 2) and expressed in oocytes. Two other mutants were produced bearing two NPT motifs (DrAqp3b-A217T) or NPA-NPT motifs (DrAqp3b-T85A/A217T). The oocytes expressing DrAqp3b-T85A showed a significant $(p<0.05) 2.4-$ and 1.5 -fold increase in $P_{\mathrm{f}}$ with respect oocytes expressing 
Table 2 Amino acid sequences of zebrafish wild-type (WT) and mutated Aqp3b

\begin{tabular}{|c|c|c|c|c|c|}
\hline Construct & Loop A & Loop B & Loop C & Loop D & Loop E \\
\hline DrAqp3b-WT & 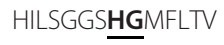 & SGGHINPIVTFSLCLLGREPWㅁKFP & FATYPSK $\underline{\mathbf{H} L T L L}$ & IVDPY NNPIPQGLEA & AVNPARDLGPRIFTAIAG \\
\hline $\mathrm{H} 53 \mathrm{~A}$ & HILSGGSAGGMFLTV & SGGHINPTVTFSLCLLGREPWRKFP & FATYPSKHLTLL & IVDPYNNPIPQGLEA & AVNPARDLGPRIFTAIAG \\
\hline G54A & HILSGGSHAMFLTV & SGGHINPTVTFSLCLLGREPWRKFP & FATYPSKHLTLL & IVDPYNNPIPQGLEA & AVNPARDLGPRIFTAIAG \\
\hline $\mathrm{H} 53 \mathrm{~A} / \mathrm{G} 54 \mathrm{H}$ & HILSGGSAHMFLTV & SGGHINPTVTFSLCLLGREPWRKFP & FATYPSKHLTLL & IVDPYNNPIPQGLEA & AVNPARDLGPRIFTAIAG \\
\hline H53A/G54H/T85A & 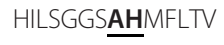 & SGGHINPAVTFSLCLLGREPWRKFP & FATYPSKHLTLL & IVDPYNNPIPQGLEA & AVNPARDLGPRIFTAIAG \\
\hline T85A & HILSGGSHGMFLTV & SGGHINPAVTFSLCLLGREPWRKFP & FATYPSKHLTLL & IVDPYNNPIPQGLEA & AVNPARDLGPRIFTAIAG \\
\hline R95A & HILSGGSHGMFLTV & SGGHINPTVTFSLCLLGAEPWRKFP & FATYPSKHLTLL & IVDPYNNPIPQGLEA & AVNPARDLGPRIFTAIAG \\
\hline E96A & HILSGGSHGMFLTV & SGGHINPTVTFSLCLLGRAPWRKFP & FATYPSKHLTLL & IVDPYNNPIPQGLEA & AVNPARDLGPRIFTAIAG \\
\hline R99A & HILSGGSHGMFLTV & SGGHINPTVTFSLCLLGREPW & FATYPSKHLTLL & IVDPYNNPIPQGLEA & AVNPARDLGPRIFTAIAG \\
\hline H154A & HILSGGSHGMFLTV & SGGHINPTVTFSLCLLGREPWRKFP & FATYPSKALLTLL & IVDPYNNPIPQGLEA & AVNPARDLGPRIFTAIAG \\
\hline G54H/H154A & HILSGGSH & SGGHINPTVTFSLCLLGREPWRKFP & FATYPSKALLTLL & IVDPYNNPIPQGLEA & AVNPARDLGPRIFTAIAG \\
\hline H53A/H154A & 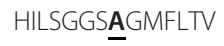 & SGGHINPTVTFSLCLLGREPWRKFP & FATYPSKA $\underline{-}$ TLL & IVDPYNNPIPQGLEA & AVNPARDLGPRIFTAIAG \\
\hline $\mathrm{H} 53 \mathrm{~A} / \mathrm{G} 54 \mathrm{H} / \mathrm{H} 154 \mathrm{~A}$ & HILSGGSAHMFLTV & SGGHINPTVTFSLCLLGREPWRKFP & FATYPSK $\underline{A} L T L L$ & IVDPYNNPIPQGLEA & AVNPARDLGPRIFTAIAG \\
\hline $\mathrm{A} 217 \mathrm{~T}$ & HILSGGSHGMFLTV & SGGHINPTVTFSLCLLGREPWRKFP & FATYPSKHLTLL & IVDPYNNPIPQGLEA & AVNPIRDLGPRIFTAIAG \\
\hline T85A/A217T & HILSGGSHGMFLTV & SGGHINPAVTFSLCLLGREPWRKFP & FATYPSKHLTLL & IVDPYNNPIPQGLEA & AVNPIRDLGPRIFTAIAG \\
\hline Y182A & HILSGGSHGMFLTV & SGGHINPTVTFSLCLLGREPWRKFP & FATYPSKHLTLL & IVDPANNPIPQGLEA & AVNPARDLGPRIFTAIAG \\
\hline
\end{tabular}

Amino acid sequence of the five loops of WT and DrAqp3b mutants. The residues mutated and the substitutions are underlined in bold.

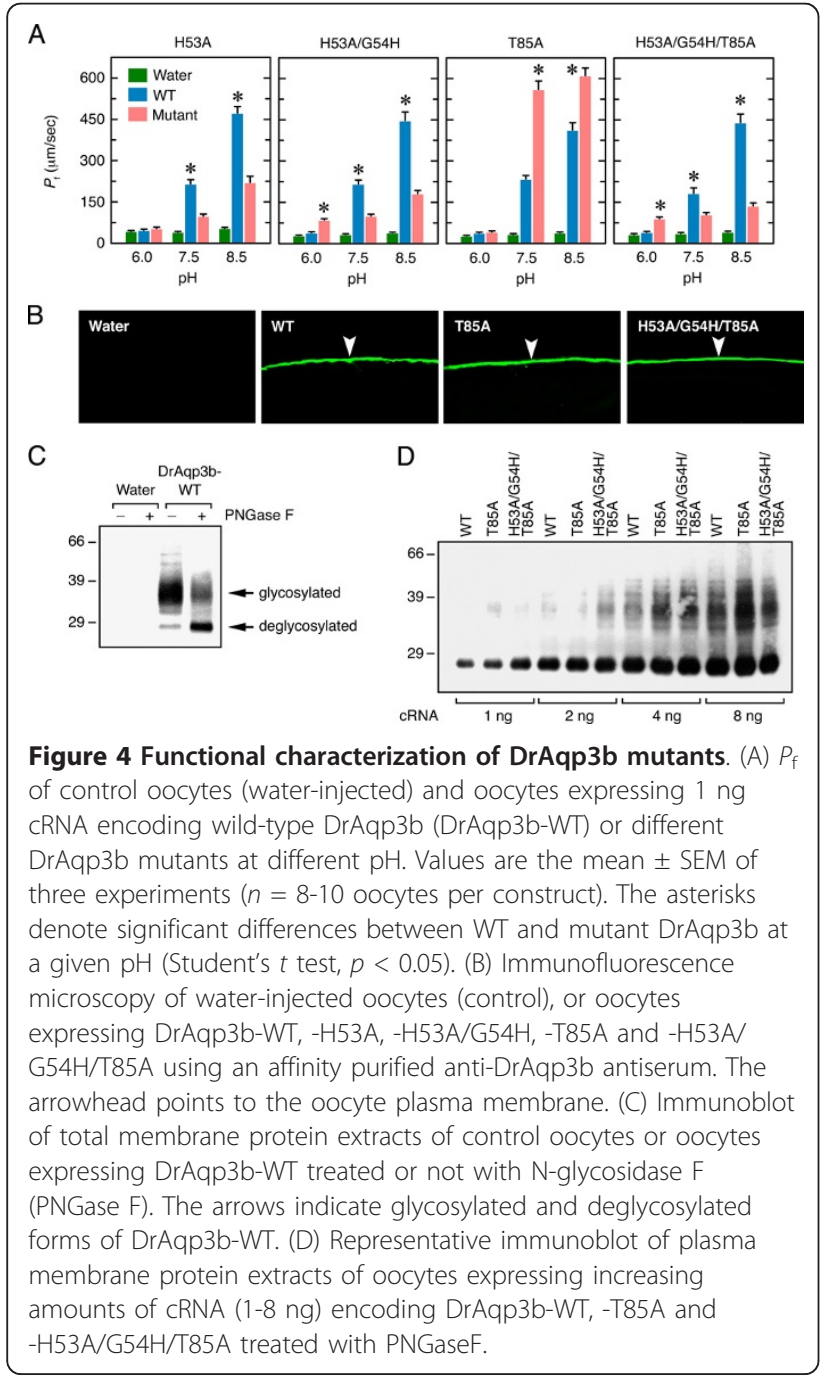

DrAqp3b-WT at pH 7.5 and 8.5, respectively, and had similar $P_{\mathrm{f}}$ at neutral and alkaline $\mathrm{pH}$ (Figure 4A). Thus, substitution of Thr by Ala in the first NPA box of DrAqp3b increased water permeability and completely abolished the stimulatory effect of alkaline $\mathrm{pH}$, although permeability was still inhibited at $\mathrm{pH} 6$. Expression of the DrAqp3b-A217T and -T85A/A217T mutants in oocytes decreased the $P_{\mathrm{f}}$ with respect the oocytes expressing DrAqp3b-WT and did not affect the $\mathrm{pH}$ sensitivity of DrAqp3b (Additional file 2).

Since the DrAqp3b-H53A/G54H mutant displayed higher water permeability at $\mathrm{pH} 6$ than the WT, and the DrAqp3b-T85A was more permeable and not affected by alkaline $\mathrm{pH}$, we finally designed and characterized a triple mutant DrAqp3b-H53A/G54H/T85A (Table 2). Interestingly, the $P_{\mathrm{f}}$ of oocytes expressing this construct was insensitive to $\mathrm{pH}$, being 2.2-fold higher than that of the DrAqp3b-WT oocytes at $\mathrm{pH} 6$ (Figure 4A). The $P_{\mathrm{f}}$ of these oocytes was, however, 2- and 3.3-times lower, respectively, than that of DrAqp3b-WT oocytes at $\mathrm{pH}$ 7.5 and 8.5 .

The mutagenesis experiments rendered two constructs, DrAqp3b-T85A and - H53A/G54H/T85A, that encoded aquaporins with enhanced water permeability at $\mathrm{pH} 7.5$ and 8.5 , or insensitive to $\mathrm{pH}$, respectively. In order to characterize the expression levels and subcellular localization of the protein products of these mutants in X. laevis oocytes, immunocytochemistry and Western blotting were carried out using an affinity-purified antibody against DrAqp3b. Immunofluorescence microscopy of oocytes expressing DrAqp3b-WT, -T85A or -H53A/ G54H/T85A revealed that in all cases the corresponding proteins were localized exclusively in the plasma 
membrane (Figure 4B). Western blot analysis of total membrane extracts of DrAqp3b-WT injected oocytes showed a broad and intense immunoreactive band of approximately 33-40 kDa (Figure 4C). This band corresponded to a glycosylated form of DrAqp3b, since treatment with N-Glycosidase F (PNGase F) rendered a product of approximately $29 \mathrm{kDa}$. Immunoblotting of plasma membrane extracts treated with PNGase F of oocytes injected with increasing amounts of DrAqp3bWT, -T85A or -H53A/G54H/T85A showed that similar amounts of the protein products were accumulated at the oocyte plasma membrane (Figure 4D). However, the DrAqp3b-H53A/G54H/T85A construct resulted in sligthly more protein at the plasma membrane in comparison with the other constructs when $1 \mathrm{ng}$ cRNA was injected into the oocytes (Figure 4D). Since oocytes expressing this mutant had lower $P_{\mathrm{f}}$ than the DrAqp3bWT and -T85A oocytes at $\mathrm{pH} 7.5$, our observations confirmed that the differences in $P_{\mathrm{f}}$ between oocytes expressing DrAqp3b-WT or the mutants were not derived from differences in translation or in the accumulation of the protein products in the oocyte membranes.

The permeability of oocytes expressing DrAqp3b-WT, $-\mathrm{T} 85 \mathrm{~A}$ or $-\mathrm{H} 53 \mathrm{~A} / \mathrm{G} 54 \mathrm{H} / \mathrm{T} 85 \mathrm{~A}$ to ethylene glycol was finally investigated by radioactive uptake assays as described previously (Figure 5). The data indicated than the permeability to ethylene glycol of oocytes expressing the different constructs followed the same pattern as the $P_{\mathrm{f}}$. Thus, the DrAqp3b-H53A/G54H/T85A oocytes showed higher ethylene glycol uptake than the other

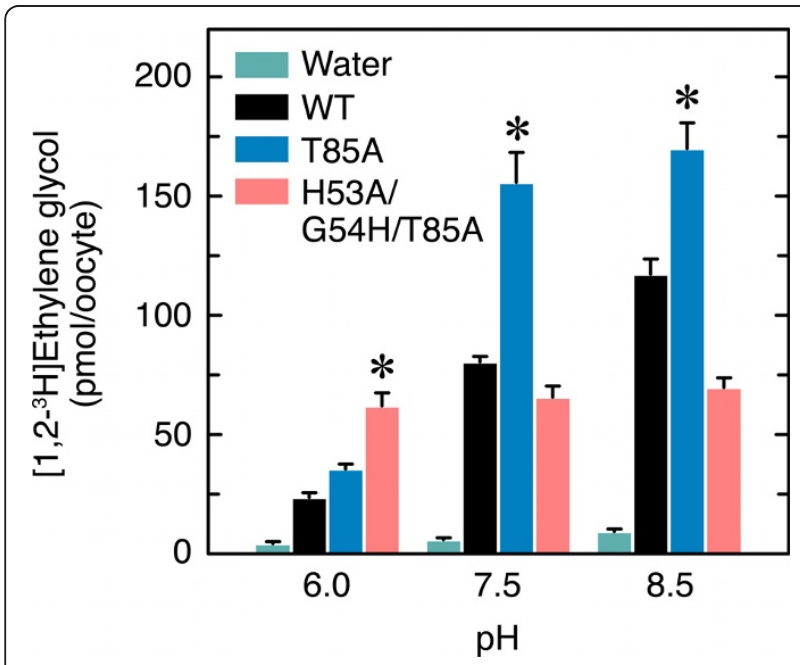

Figure 5 Ethylene glycol uptake of DrAqp3b-WT and mutants at different $\mathrm{pH}$. Uptake of radiolabeled ethylene glycol by oocytes injected with water or with $5 \mathrm{ng}$ of DrAqp3b-WT, -T85A or -H53A/ $\mathrm{G} 54 \mathrm{H} / \mathrm{T} 85 \mathrm{~A}$ cRNA was determined as in Figure 2. Data (mean \pm SEM; $n=8-10$ oocytes) with an asterisk are significantly (ANOVA, $p$ $<0.01)$ different from the DrAqp3b-WT. oocytes at $\mathrm{pH} 6$, and the uptake did not change at higher $\mathrm{pH}$. In contrast, at $\mathrm{pH} 7.5$ and 8.5 the DrAqp3bT85A oocytes showed the highest ethylene glycol uptake.

\section{Permeability of DrAqp3b mutants under hypertonic conditions}

The permeability to water and ethylene glycol of oocytes expressing HsAQP3, DrAqp3b-WT, -T85A or -H53A/ $\mathrm{G} 54 \mathrm{H} / \mathrm{T} 85 \mathrm{~A}$ was subsequently determined in hypertonic solutions (Figure 6). We first investigated the hydraulic conductivity $\left(L_{\mathrm{p}}\right)$ of oocytes expressing $1 \mathrm{ng}$ of cRNA of the different constructs immersed in a sucrose solution $(0.9 \mathrm{M})$. Oocytes from all groups shrank quickly during approximately the first $2 \mathrm{~min}$ of sucrose exposure, and the shrinkage decreased thereafter, indicating that they were slowly reaching the equilibration state (Figure 6A). As expected, aquaporin-expressing oocytes shrank faster than the controls, although the oocytes expressing DrAqp3b-T85A shrank more rapidly than the oocytes expressing the other constructs (Figure 6A). Since we observed that the shrinkage of oocytes in $0.9 \mathrm{M}$ sucrose was linear only during the first $2 \mathrm{~min}$, we calculated the $L_{\mathrm{p}}$ after 2 and $10 \mathrm{~min}$; the $L_{\mathrm{p}}$ at $2 \mathrm{~min}$ being more comparable to the $P_{\mathrm{f}}$ previously determined under hypotonic conditions. Accordingly, the $L_{\mathrm{p}}$ values after $2 \mathrm{~min}$ of the DrAqp3b-T85A oocytes were the highest, followed by the oocytes expressing DrAqp3b-WT, -H53A/G54H/ T85A, HsAQP3 and water-injected oocytes (Table 3). After $10 \mathrm{~min}$, the $L_{\mathrm{p}}$ of the DrAqp3b-T85A oocytes remained higher than that of the other groups, whereas the $L_{\mathrm{p}}$ of the DrAqp3b-WT, -H53A/G54H/T85A and HsAQP3 oocytes was similar and higher than the control oocytes (Table 3). Therefore, the results confirmed that the DrAqp3b-T85A mutant was also the most permeable to water under hypertonic conditions.

Next, we evaluated the $L_{\mathrm{p}}$ and $P_{\mathrm{EG}}$ of oocytes expressing the different constructs under a high concentration gradient of ethylene glycol $(1.3 \mathrm{M})$ for $10 \mathrm{~min}$. For these experiments, we used oocytes expressing 1 or $20 \mathrm{ng}$ of cRNA. The relative volume changes of the oocytes under these conditions revealed that water-injected oocytes shrank and did not swell for almost $10 \mathrm{~min}$, suggesting that ethylene glycol permeated oocytes quite slowly (Figure 6B and 6C). HsAQP3- and DrAqp3bH53A/G54H/T85A-expressing oocytes (1 ng cRNA) shrank slightly less than controls, and then swelled slowly, indicating a higher permeability to the cryoprotectant (Figure 6B). The DrAqp3b-WT oocytes shrank less and swelled more than those injected with DrAqp3b-H53A/G54H/T85A- or HsAQP3, whereas oocytes expressing DrAqp3b-T85A exhibited few shrinkage and the fastest re-swelling (Figure 6B). Accordingly, the $L_{\mathrm{p}}$ values of the DrAqp3b-T85A oocytes in $1.3 \mathrm{M}$ 


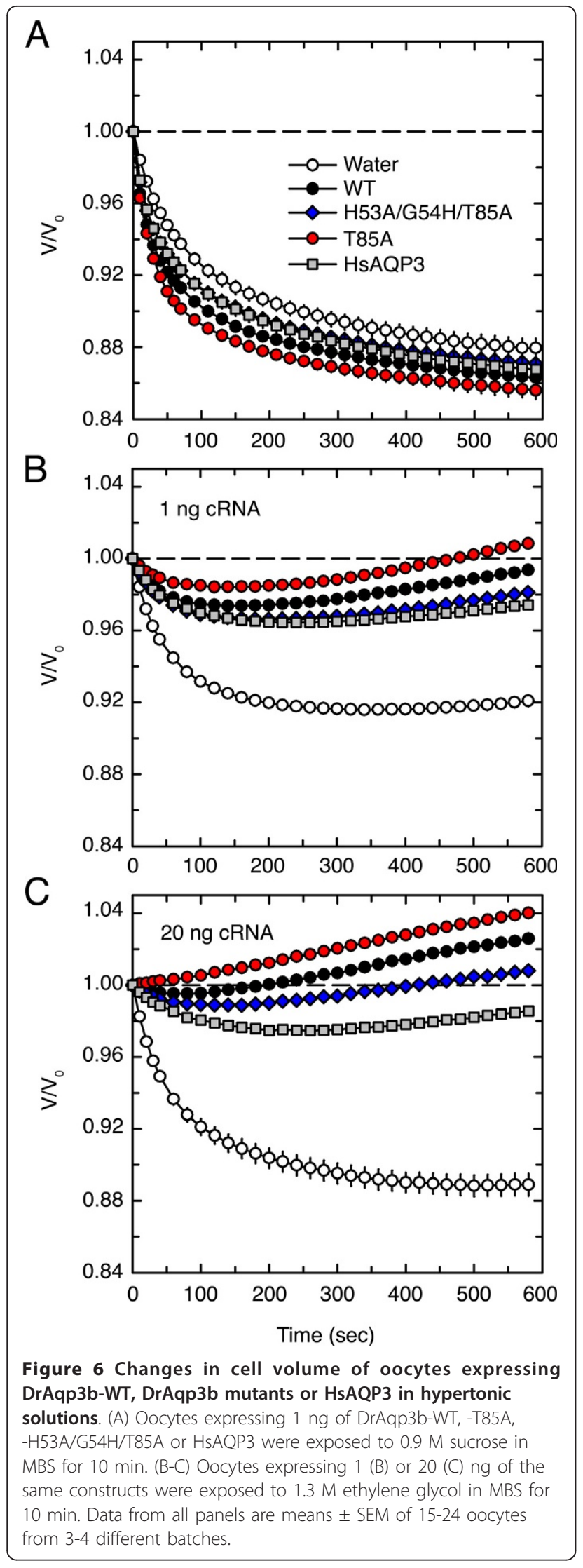

Table 3 Hydraulic conductivity $\left(L_{p}\right)$ of $X$. laevis oocytes expressing wild-type (WT) DrAqp3b, DrAqp3b mutants or HsAQP3 determined after $\mathbf{2}$ or $\mathbf{1 0} \mathrm{min}$ in a sucrose solution

\begin{tabular}{lll}
\hline & \multicolumn{2}{c}{$\boldsymbol{L}_{\mathbf{p}}(\boldsymbol{\mu} \mathbf{m} / \mathbf{m i n} / \mathbf{a t m})$} \\
\cline { 2 - 3 } & $\mathbf{2} \mathbf{~} \boldsymbol{1 n}$ & $\mathbf{1 0} \mathbf{~} \boldsymbol{m i n}$ \\
\hline Water & $1.40 \pm 0.06^{\mathrm{a}}$ & $0.69 \pm 0.03^{\mathrm{a}}$ \\
DrAqp3b-WT & $2.15 \pm 0.06^{\mathrm{c}}$ & $0.89 \pm 004^{\mathrm{b}}$ \\
DrAqp3b-H53A/G54H/T85A & $1.94 \pm 0.08^{\mathrm{b}}$ & $0.88 \pm 004^{\mathrm{b}}$ \\
DrAqp3b-T85A & $2.57 \pm 0.07^{\mathrm{d}}$ & $1.02 \pm 0.04^{\mathrm{c}}$ \\
HsAQP3 & $1.93 \pm 0.07^{\mathrm{b}}$ & $0.87 \pm 0.03^{\mathrm{b}}$ \\
\hline
\end{tabular}

Values (mean \pm SEM) for water- and aquaporin-injected (1 ng cRNA) oocytes are calculated from the data in Figure 6A. Data from the same column with different superscript are statistically significant (ANOVA, $p<0.05$ ).

ethylene glycol were the highest, followed by the DrAqp3b-WT, -H53A/G54H/T85A, HsAQP3, and control oocytes (Table 4). This was in agreement with the data obtained using oocytes exposed to $0.9 \mathrm{M}$ sucrose. The $P_{\text {EG }}$ values also corroborated previous volumetric and ethylene glycol uptake experiments, since the $P_{\mathrm{EG}}$ of DrAqp3b-T85A oocytes was significantly $(p<0.05)$ higher than that of the oocytes expressing the other constructs or injected with water (Table 4). The reflection coefficients $(\sigma)$, calculated using the Kedem-Katchalsky model (see Methods), were the lowest in aquaporin-expressing oocytes (data not shown), suggesting that water and solute permeate through the same pore.

In general, oocytes injected with $20 \mathrm{ng}$ of cRNA of each construct shrank less and swelled more rapidly over the $10 \mathrm{~min}$ period when compared with oocytes expressing $1 \mathrm{ng}$ (Figure 6C). For the DrAqp3b-T85A oocytes, however, no shrinkage was observed but the

Table 4 Hydraulic conductivity $\left(L_{p}\right)$ and ethylene glycol permeability $\left(P_{\mathrm{EG}}\right)$ of $X$. laevis oocytes expressing wildtype (WT) DrAqp3b, two DrAqp3b mutants or HsAQP3, in hypertonic ethylene glycol solution

\begin{tabular}{lll}
\hline & $\begin{array}{l}L_{p}(\mu \mathrm{m} / \mathbf{m i n} / \\
\mathbf{a t m})\end{array}$ & $\begin{array}{l}P_{\mathrm{EG}}\left(\mathbf{x ~ 1 0 ^ { - 3 }} \mathrm{cm} /\right. \\
\mathbf{m i n})\end{array}$ \\
\hline Water & $0.36 \pm 0.02^{\mathrm{a}}$ & $0.47 \pm 0.03^{\mathrm{a}}$ \\
DrAqp3b-WT (1 ng) & $2.15 \pm 0.14^{\mathrm{c}}$ & $17.59 \pm 0.83^{\mathrm{d}}$ \\
DrAqp3b-H53A/G54H/T85A (1 & $1.55 \pm 0.13^{\mathrm{b}}$ & $13.06 \pm 0.72^{\mathrm{c}}$ \\
ng) & & \\
DrAqp3b-T85A (1 ng) & $2.64 \pm 0.15^{\mathrm{d}}$ & $25.49 \pm 1.56^{\mathrm{e}}$ \\
HsAQP3 (1 ng) & $1.31 \pm 0.08^{\mathrm{b}}$ & $10.73 \pm 0.59^{\mathrm{b}}$ \\
DrAqp3b-WT (20 ng) & $2.63 \pm 0.07^{\mathrm{d}}$ & $40.06 \pm 1.22^{\mathrm{c}}$ \\
DrAqp3b-H53A/G54H/T85A (20 & $2.27 \pm 0.07^{\mathrm{c}}$ & $36.58 \pm 1.74^{\mathrm{c}}$ \\
ng) & & \\
DrAqp3b-T85A (20 ng) & $3.24 \pm 0.08^{\mathrm{e}}$ & $53.91 \pm 2.55^{\mathrm{d}}$ \\
HsAQP3 (20 ng) & $1.96 \pm 0.08^{\mathrm{b}}$ & $22.24 \pm 0.95^{\mathrm{b}}$ \\
\hline
\end{tabular}

Values (mean \pm SEM) for water- and aquaporin-injected (1 or $20 \mathrm{ng}$ CRNA) oocytes are calculated from the data in Figure $6 \mathrm{~B}$ and $\mathrm{C}$. For each CRNA dose, data with different superscript are statistically significant (ANOVA, $p<0.05$ ). 
oocytes constantly swelled, probably reflecting a very fast permeation of ethylene glycol into the oocyte. Consistently, 20 ng cRNA-injected oocytes had higher $L_{\mathrm{p}}$ and $P_{\text {EG }}$ values than those injected with $1 \mathrm{ng}$ and, as observed before, oocytes expressing DrAqp3b-T85A showed the highest $L_{\mathrm{p}}$ and $P_{\mathrm{EG}}$ values (Table 4).

The internal concentration of ethylene glycol in waterinjected oocytes and oocytes expressing the different constructs after immersion in hypertonic ethylene glycol was finally assessed. For these experiments, oocytes were exposed for $10 \mathrm{~min}$ to a solution of $1.3 \mathrm{M}$ ethylene glycol at pH 7.5 containing radiolabeled ethylene glycol. The results confirmed that the uptake of the cryoprotectant was highly increased under a concentration gradient (Table 5), since oocytes expressing $1 \mathrm{ng}$ cRNA of the different constructs showed about 150-fold higher uptake rate of ethylene glycol than oocytes expressing 5 ng (Figure 5) or $20 \mathrm{ng}$ (Figure 2) cRNA that were exposed to an isotonic ethylene glycol solution at the same $\mathrm{pH}$. After $10 \mathrm{~min}$ in $1.3 \mathrm{M}$ ethylene glycol, the internal concentration of the cryoprotectant in oocytes injected with 1 o $20 \mathrm{ng}$ cRNA of DrAqp3b-T85A was 2.7- and 3.6-times higher, respectively, than that of control oocytes (Table 5). The ethylene glycol concentration in oocytes expressing 1 or 20 ng cRNA of DrAqp3bWT, -H53A/G54H/T85A, and HsAQP3 was significantly $(p<0.05)$ lower than that of DrAqp3b-T85A oocytes, but still higher than in control oocytes (Table 5).

\section{Discussion}

In the present study, we have characterized the permeability of the complete repertoire of zebrafish GLPs to glycerol, propylene glycol and ethylene glycol in X. laevis oocytes. We found that the two zebrafish Aqp3

\begin{tabular}{|c|c|c|}
\hline & \multicolumn{2}{|c|}{ cRNA injected } \\
\hline & $1 \mathrm{ng}$ & $20 \mathrm{ng}$ \\
\hline Water & \multicolumn{2}{|c|}{$\begin{array}{l}0.11 \pm 0.004^{a} \\
(6050 \pm 220)\end{array}$} \\
\hline DrAqp3b-WT & $\begin{array}{c}0.24 \pm 0.01^{c} \\
(14568 \pm 607)\end{array}$ & $\begin{array}{c}0.34 \pm 0.02^{d} \\
(21284 \pm 1250)\end{array}$ \\
\hline DrAqp3b-H53A/G54H/T85A & $\begin{array}{c}0.20 \pm 0.01^{b} \\
(11980 \pm 599)\end{array}$ & $\begin{array}{c}0.29 \pm 0.01^{c} \\
(17835 \pm 615)\end{array}$ \\
\hline DrAqp3b-T85A & $\begin{array}{l}0.33 \pm 0.02^{d} \\
(20328 \pm 1232)\end{array}$ & $\begin{array}{l}0.43 \pm 0.01^{\mathrm{e}} \\
(27305 \pm 635)\end{array}$ \\
\hline HSAQP3 & $\begin{array}{l}0.20 \pm 0.01^{b} \\
(11900 \pm 595)\end{array}$ & $\begin{array}{l}0.24 \pm 0.01^{b} \\
(14448 \pm 602)\end{array}$ \\
\hline
\end{tabular}

Data are the mean \pm SEM ( $n=12-18$ oocytes) of two different experiments. Data in parenthesis are in pmol/oocyte/min. Values from the same column with different superscript are statistically significant (ANOVA, $p<0.05$ ). isoforms, although $\mathrm{pH}$ dependent, are selectively more permeable to ethylene glycol than to glycerol or propylene glycol under isotonic conditions. Using this property, apparently unique among vertebrate aquaporins, we have developed two mutant constructs based on the amino acid sequence of DrAqp3b. One of these mutants was $\mathrm{pH}$ insensitive when expressed in oocytes, whereas the other showed higher water and ethylene glycol permeability than the WT in both isotonic and hypertonic solutions.

It is known that some mammalian aquaporins are regulated by $\mathrm{pH}$, namely $\mathrm{AQP0},-3$ and $-6[44,50,56,57]$. However, the effect of $\mathrm{pH}$ on the permeability of teleost GLPs has not been reported, except for Aqp3a and -3b $[58,59]$. The results from the present study show that water, glycerol and propylene glycol permeability of oocytes expressing HsAQP3 at pH 6 was reduced to a similar extent as in previous studies, whereas permeability remained unchanged between $\mathrm{pH} 7.5$ and 8.5 $[44,49,60]$. Zebrafish Aqp3a, $-3 \mathrm{~b},-7$ and $-10 \mathrm{~b}$ were affected to a variable degree by changes in $\mathrm{pH}$ when expressed in oocytes, although DrAqp3a and -3b were the most affected aquaporins. Thus, water and cryoprotectant permeability of oocytes expressing DrAqp3a or $-3 \mathrm{~b}$ was completely abolished at pH 6 and was highest at $\mathrm{pH}$ 8.5. Such an effect of $\mathrm{pH}$ on aquaporin permeability, not observed in HsAQP3, has been previously reported for the Aqp3a and -3b from killifish and European eel, respectively $[58,59]$, but its physiological significance remains to be elucidated. The $P_{\mathrm{f}}$ of oocytes expressing DrAqp7 or $-10 \mathrm{~b}$ was also diminished at acidic $\mathrm{pH}$, but only by approximately $50 \%$, a feature that has not been described for the mammalian orthologs.

Determination of the $P_{\mathrm{Gly}}, P_{\mathrm{PG}}$ and $P_{\mathrm{EG}}$ of oocytes expressing the different zebrafish GLPs under isotonic conditions indicated that DrAqp3a and -3b were the only aquaporins more permeable to ethylene glycol than to glycerol or propylene glycol. HsAQP3 was more permeable to glycerol than to the other cryoprotectants under isotonic conditions at $\mathrm{pH} 7.5$ and 8.5 , but under high concentration gradients HsAQP3 might transport propylene glycol and ethylene glycol as efficiently as glycerol, as it occurs for rat AQP3 expressed in X. laevis oocytes [31]. Therefore, it is possible that in hypertonic solutions oocytes expressing DrAqp3a or -3b may be equally permeable to glycerol, propylene glycol and ethylene glycol. Nevertheless, our results indicate that oocytes expressing DrAqp3b and exposed to isotonic or hypertonic ethylene glycol solutions permeate this cryoprotectant more efficiently than those expressing HsAQP3. The DrAqp3b amino sequence shows the residues forming the ar/ $R$ narrowest constriction region conserved in GLPs, but interestingly, it shows an unusual first NPA motif, where Ala is substituted by 
Thr. This amino acid change may be involved in the increased permeability of DrAqp3b to ethylene glycol with respect glycerol or propylene glycol, since NPA motifs form one of the constriction sites of aquaporins responsible for proton exclusion and size selectivity [61]. However, the observation that changing the NPT motif of DrAqp3b into NPA increased both water and ethylene glycol permeability does not support this supposition. The molecular basis of DrAqp3b ethylene glycol selectivity remains thus unclear and needs to be investigated.

Ethylene glycol is one of the most suitable cryoprotectants in terms of efficiency/toxicity ratio for the preservation of oocytes and embryos from higher vertebrates [13-18], as well as from some fish species [3], and therefore DrAqp3b may be more effective than mammalian AQP3 at increasing the internal concentration of ethylene glycol. Water and solute transport through DrAqp3b is however $\mathrm{pH}$ sensitive being maximum at $\mathrm{pH}$ 8.5. To counteract this obstacle, we investigated the role of sequence motifs in DrAqp3b potentially critical for $\mathrm{pH}$ regulation of water permeability, or that can enhance ethylene glycol permeability. Mutagenesis experiments identified one His residue in loop A of DrAqp3b $\left(\mathrm{His}^{53}\right)$, spanning the outer region of the pore, which precise position within the loop regulated the inhibitory effect of acidic $\mathrm{pH}$ on water permeability. These observations are similar to those reported by Németh-Cahalan et al. [51] for the fish and bovine AQPO. In this study, it was suggested that $\mathrm{pH}$ can modulate the orientation of water molecules in the pore by titrating external His, which would in turn alter the orientation-dependant electrostatic interactions between water molecules, thus affecting their effective binding energies within the pore. In the present work, we also found that changing the first NPT motif of DrAqp3b into NPA (DrAqp3b-T85A) shifted the maximal permeability to $\mathrm{pH} 7.5$, allowing for higher water and ethylene glycol permeability at $\mathrm{pH} 7.5$ and 8.5 with respect the WT. These findings suggest that $\mathrm{Thr}^{85}$ of DrAqp3b is involved in the sensitivity of this aquaporin to alkaline $\mathrm{pH}$. By combining these two observations, a triple mutant was designed (DrAqp3b-H53A/G54H/T85A) which was no longer $\mathrm{pH}$ sensitive (e.g., exhibited similar permeability at all $\mathrm{pHs}$ ), although it was less permeable at $\mathrm{pH} 7.5$ and 8.5 than the WT.

Increasing cell permeability to water and cryoprotectants, under high concentration gradients, is important for developing and improving cryopreservation protocols [31]. During slow and fast (vitrification) cooling procedures employed for cryopreservation, cells have to be exposed to variable concentrations (around $1.5 \mathrm{M}$, or $>5 \mathrm{M}$, respectively) of cryoprotectants $[14,62]$. Our results suggest that mutated DrAqp3b, with improved cryoprotectant permeability, may be useful in cryobiology. The $L_{\mathrm{p}}$ and $P_{\text {EG }}$ of oocytes expressing HsAQP3, DrAqp3b-WT, -T85A- or -H53A/G54H/T85A were measured here in a solution containing $1.3 \mathrm{M}$ ethylene glycol equivalent to that used in slow cooling protocols. For both 1- or $20 \mathrm{ng}$ cRNA-injected oocytes, the $L_{\mathrm{p}}$ and $P_{\mathrm{EG}}$ values were the highest for oocytes expressing DrAqp3b-T85A in agreement with previous observations using isotonic conditions and a solution of $0.9 \mathrm{M}$ sucrose. The $P_{\mathrm{EG}}$ values of oocytes injected with $20 \mathrm{ng}$ of DrAqp3b-WT or $-\mathrm{T} 85 \mathrm{~A}$ and exposed to $1.3 \mathrm{M}$ ethylene glycol were $40.06 \times 10^{-3}$ and $53.91 \times 10^{-3} \mathrm{~cm} / \mathrm{min}$, respectively, whereas those of the HsAQP3-expressing oocytes were $22.24 \times 10^{-3} \mathrm{~cm} / \mathrm{min}$. Yamaji et al. [31] reported a $P_{\mathrm{EG}}$ of $33.5 \times 10^{-3} \mathrm{~cm} / \mathrm{min}$ of $X$. laevis oocytes expressing $40 \mathrm{ng}$ of rat AQP3 and exposed to the same ethylene glycol concentration. Our results therefore suggest that DrAqp3b-WT and -T85A may transport ethylene glycol more efficiently than human or rat AQP3. However, the $L_{\mathrm{p}}(0.02 \mu \mathrm{m} / \mathrm{min} / \mathrm{atm})$ and $P_{\mathrm{EG}}$ $\left(0.11 \times 10^{-3} \mathrm{~cm} / \mathrm{min}\right)$ of water-injected oocytes reported by Yamaji et al. [31] were 18- and 4-times lower, respectively, than those measured in our study $(0.36 \mu \mathrm{m} / \mathrm{min} /$ atm and $0.47 \times 10^{-3} \mathrm{~cm} / \mathrm{min}$, respectively) under the same conditions. The causes of these differences remain unknown, but they may be related with the observation that water-injected oocytes shrank faster in our study than those of Yamaji et al. [31] at a similar ethylene glycol concentration. Also, we consistently measured a basal ethylene glycol permeation, under either isotonic or hypertonic solutions, in water-injected oocytes, in both swelling and radiolabeled solute uptake assays.

\section{Conclusions}

In the present study, we have shown that the $\mathrm{pH}$ sensitiveness and ethylene glycol permeability of DrAqp3b can be altered by single or triple point mutations in its amino acid sequence. Using this approach, we engineered and functionally characterized two mutant constructs, DrAqp3b-T85A- and -H53A/G54H/T85A, which were either more permeable to water and ethylene glycol than the DrAqp3b-WT or were $\mathrm{pH}$ insensitive, respectively. These artificial aquaporins may be useful for cryopreservation of large cells or multicellular systems, and investigations in this direction are underway.

\section{Methods}

\section{Aquaporin cDNAs and expression constructs}

The GenBank accession numbers of the zebrafish aquaporin cDNAs employed in this study were as follows: Aqp1a (AY626937), Aqp3a (EU341833), Aqp3b (EU341832), Aqp7 (FJ655385), Aqp9a (FJ655387), Aqp9b (EU341835), Aqp10a (FJ655388), and Aqp10b (EU341836). The human AQP3 cDNA (GenBank 
accession number BC013566) was generously provided by Prof. Peter Deen (Radboud University Nijmegen Medical Centre, The Netherlands).

Aquaporin constructs for heterologous expression in $X$. laevis oocytes were generated by subcloning fulllength aquaporin cDNAs into the pT7Ts expression vector [63]. Since this vector contains unique BglII, EcoRV and SpeI cloning sites to allow the gene of interest to be flanked by the 5' and 3' untranslated regions of the $X$. laevis $\beta$-globin gene, compatible BglII, EcoRV or SpeI sites were introduced for each aquaporin (depending on the restriction sites identified in the sequence) by PCR using high fidelity polymerase (Easy A, Stratagene). Mutations into the DrAqp3b amino acid sequence were performed on pT7Ts-DrAqp3b plasmid using the Quickchange site-directed mutagenesis kit (Stratagene) and the oligonucleotide primers listed in Additional file 3. Selected clones were sequenced by BigDye Terminator v3.1 cycle sequencing on ABI PRISM 377 DNA analyzer (Applied Biosystems) to confirm that only the desired mutations were produced.

\section{Sequence analysis}

Vertebrate and teleost aquaporin sequences were retrieved from the NCBI database [64]. Amino acid sequence alignments were performed using the ClustalW multiple sequence alignment program [65] employing the full-length amino acid sequence, and were manually optimized using the Bioedit software [66].

\section{Functional expression in X. laevis oocytes}

The cRNAs for microinjection were synthesized with T7 RNA polymerase (Roche) from XbaI or SalI-linearized pT7Ts-aquaporin (depending on the restriction sites identified in the aquaporin sequence). Isolation of stages $\mathrm{V}$ and VI oocytes and microinjection was performed as previously described [63]. Oocytes were transferred to MBS (88 mM NaCl, $1 \mathrm{mM} \mathrm{KCl,} 2.4 \mathrm{mM} \mathrm{NaHCO}, 0.82$

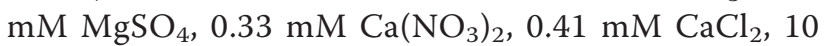
$\mathrm{mM}$ HEPES, and $25 \mu \mathrm{g} / \mathrm{ml}$ gentamycin, $\mathrm{pH} 7.5)$ and injected with $50 \mathrm{nl}$ of distilled water (negative control) or $50 \mathrm{nl}$ of water solution containing 1 to $20 \mathrm{ng}$ of cRNA. One day after injection, oocytes were manually defolliculated and subsequently maintained in MBS at $18^{\circ} \mathrm{C}$.

\section{Determination of oocyte $P_{\mathrm{f}}, P_{\mathrm{GLY}}, P_{\mathrm{PG}}$ and $P_{\mathrm{EG}}$ at different $\mathrm{pH}$}

Water and solute permeability of oocytes expressing the different constructs was tested in hypotonic or isotonic MBS (200 mOsm), respectively, at different $\mathrm{pH}$ and at room temperature $\left(20^{\circ} \mathrm{C}\right)$. For the calculation of $P_{\mathrm{f}}$, two days after injection the oocytes were transferred to isotonic MBS (200 mOsm) at $\mathrm{pH} 6,7.5$ or 8.5 for 15 min, and then transferred to 10-fold diluted MBS (20 $\mathrm{mOsmol}$ ) at the same experimental $\mathrm{pH}$. Oocyte swelling was followed by video microscopy using serial images at $2 \mathrm{sec}$ intervals during the first $20 \mathrm{sec}$ period using a Nikon Color view video camera coupled to a stereomicroscope (SMZ1000, Nikon). The $P_{\mathrm{f}}$ values were calculated taking into account the time-course changes in relative oocyte volume $\left[\mathrm{d}\left(\mathrm{V} / \mathrm{V}_{0}\right) / \mathrm{dt}\right]$, the partial molar volume of water $\left(\mathrm{V}_{\mathrm{W}}=18 \mathrm{~cm}^{3} / \mathrm{mol}\right)$ and the oocyte surface area $(\mathrm{S})$ using the formula $\mathrm{V}_{0}\left[\mathrm{~d}\left(\mathrm{~V} / \mathrm{V}_{0}\right) / \mathrm{dt}\right] /\left[\mathrm{SV} \mathrm{W}_{\mathrm{W}}\right.$ $\left.\left(\mathrm{Osm}_{\mathrm{in}}-\mathrm{Osm}_{\text {out }}\right)\right]$. The surface area of the oocyte was considered to be nine times the apparent area because membrane folding [67].

Cryoprotectant (glycerol, propylene glycol and ethylene glycol; Sigma) permeability of water-injected and aquaporin-expressing oocytes was determined also volumetrically in isotonic MBS, where $\mathrm{NaCl}$ was replaced by 160 $\mathrm{mM}$ of the solutes, at different $\mathrm{pH}$. The osmolarity of the solutions was measured for each experiment with a vapor pressure osmometer (Vapro ${ }^{\circledR} 5520$, Wescor), and adjusted to $200 \mathrm{mOsm}$ with $\mathrm{NaCl}$ if necessary. Oocytes were exposed to different $\mathrm{pH}$ as indicated above, and oocyte swelling was measured by video microscopy, in this case using serial images at $5 \mathrm{sec}$ intervals during 1 min. In some experiments, the $P_{\mathrm{EG}}$ was estimated using MBS containing 60 or $100 \mathrm{mM}$ ethylene glycol and using serial images of oocyte swelling as for the $P_{\mathrm{f}}$. The $P_{\mathrm{GLY}}$, $P_{\mathrm{PG}}$ and $P_{\mathrm{EG}}$ were calculated from oocyte swelling using the formula $\left[\mathrm{d}\left(\mathrm{V} / \mathrm{V}_{0}\right) \mathrm{dt}\right] /\left(\mathrm{S} / \mathrm{V}_{0}\right)[68]$. The $P_{\mathrm{s}}$ of oocytes for each of the three cryoprotectants was measured using the same batch of oocytes.

To ensure that the $P_{\mathrm{f}}$ was not affected by ion dilution during oocyte volume measurements [69], the $\mathrm{NaCl}$ concentration of MBS was reduced to $78 \mathrm{mM}, 50 \mathrm{mM}$ or $25 \mathrm{mM}$, and sucrose was added to a concentration of $20 \mathrm{mM}, 56 \mathrm{mM}$ and $126 \mathrm{mM}$, respectively, to obtain isotonic solutions as determined with the vapor pressure osmometer. Oocytes were then equilibrated in these solutions at pH 7.5 for $45 \mathrm{~min}$, and subsequently transferred to the same solutions at $\mathrm{pH} 6,7.5$ or 8.5 for 15 min. Oocyte swelling was measured in these solutions that were made hyposmotic by removing sucrose, and thus the ion concentrations were constant. The same control experiments were carried out for the determination of $P_{\mathrm{EG}}$ at different $\mathrm{pH}$. For this, oocytes were equilibrated in isotonic MBS containing $38 \mathrm{mM} \mathrm{NaCl}$ and $100 \mathrm{mM}$ sucrose, which was substituted by $100 \mathrm{mM}$ ethylene glycol for the swelling measurements.

\section{Determination of the osmotically inactive fraction of $X$. laevis oocytes}

The water loss of non-injected $X$. laevis oocytes was assessed by two types of experiments performed at $\mathrm{pH}$ 
7.5 and room temperature. In the first experiment, oocytes were exposed to a high concentrated sucrose solution $(0.9 \mathrm{M}, 1450 \mathrm{mOsm})$ and the diameter of the oocytes was recorded after $10 \mathrm{~min}$ and $1 \mathrm{~h}$. Oocytes were also weighed before and after $1 \mathrm{~h}$ of exposure to sucrose. With these data (not shown), we determined that oocytes did not lose more than $25 \%$ of their volume or weight, which corresponds to the free water content. For further calculations (see below), the osmotically inactive volume was taken as $75 \%$ of the initial oocyte volume. From subsequent experiments, where oocytes were dried in a oven during $24 \mathrm{~h}$, we estimated that the bound water associated with osmotically inactive volume of oocytes is $45 \%$ of the total water of the oocyte (data not shown).

\section{Measurement of water and cryoprotectant permeability of oocytes in hypertonic solutions}

The $L_{\mathrm{p}}$ and $P_{\mathrm{EG}}$ of water- and aquaporin-injected oocytes were calculated from their relative volume changes when exposed to $0.9 \mathrm{M}$ sucrose (1460 mOsm) or $1.3 \mathrm{M}$ ethylene glycol $(1600 \mathrm{mOsm})$ in MBS at pH 7.5 for $10 \mathrm{~min}$ at room temperature. Within this time period, the compounds were not toxic for the oocytes. The change in oocyte volume were recorded every $10 \mathrm{sec}$ with a video camera as described above. The data were entered into the DIFFCHAM software [70] which allows to estimate, based on the change in concentration of the solutes and the original volume of the oocyte, values of $L_{\mathrm{p}}, P_{\mathrm{EG}}$ and $\sigma$ for individual oocytes according to the Kedem-Katchalsky model (K-K model) [71] of movement of solutes across cell membranes (see [72] for details). The software was instructed to model for an extracellular step rise in sucrose or ethylene glycol concentration, from 0 to $0.9 \mathrm{M}$ or from 0 to $1.3 \mathrm{M}$, respectively, with a non-permeating solute of $200 \mathrm{mOsm}$ corresponding to the MBS solution. The partial molar volume of ethylene glycol was $54 \mathrm{~cm}^{3} /$ mol, and the gas constant (R) was $82.3 \mathrm{~cm}^{3} / \mathrm{atm} / \mathrm{mol}$ [31]. The osmotically inactive volume was $75 \%$ of the initial oocyte volume as determined above. Five to seven oocytes per construct were analyzed individually for each batch of oocytes. In these experiments, the $P_{\mathrm{f}}$ can be calculated using the formula LpRT/Vw.

\section{Radioactive ethylene glycol uptake assays}

The uptake of $\left[1,2-{ }^{3} \mathrm{H}\right]$ ethylene glycol (American Radiolabelled Chemicals Inc.; $20 \mathrm{Ci} / \mathrm{mmol}$ ) was determined in oocytes exposed to isotonic and hypertonic solutions at room temperature. Under isotonic conditions, groups of 10 oocytes injected with water or aquaporin cRNA were incubated in $200 \mu \mathrm{l}$ of isotonic MBS at different $\mathrm{pH}$ containing $5 \mu \mathrm{M}(20 \mu \mathrm{Ci})\left[1,2-{ }^{3} \mathrm{H}\right]$ ethylene glycol, and cold ethylene glycol was added to give $1 \mathrm{mM}$ final concentration. After $1 \mathrm{~min}$ (including zero time for subtraction of the signal from externally bound solute), oocytes were washed rapidly in ice-cold MBS three times, and individual oocytes were dissolved for at least $1 \mathrm{~h}$ in $400 \mu \mathrm{l}$ of $10 \%$ SDS for scintillation counting.

To determine the ethylene glycol content of oocytes exposed to hypertonic $1.3 \mathrm{M}$ ethylene glycol solution in MBS at $\mathrm{pH} 7.5$, the protocol was the same than above, except that the exposure to the ethylene glycol solution was for $10 \mathrm{~min}$, and the washing was carried out in MBS containing $1.3 \mathrm{M}$ ethylene glycol. An amount of $12 \mu \mathrm{Ci}$ of $\left[1,2-{ }^{3} \mathrm{H}\right]$ ethylene glycol was added to $120 \mu \mathrm{l}$ of $1.3 \mathrm{M}$ in MBS containing 6 oocytes (resulting in 73000 $\mathrm{cpm} / \mu \mathrm{l}$ ). The final concentration (in $\mathrm{mol} / \mathrm{l}$ ) of ethylene glycol in each oocyte after $10 \mathrm{~min}$ exposure was determined with the formula: $\left[\left(\mathrm{T}_{10^{-}}-\mathrm{T}_{0}\right) / 73000\right] \times 1.3 \mu \mathrm{mol} /$ $\mathrm{V}$; where $\mathrm{T}_{10}$ are the cpm in oocytes after $10 \mathrm{~min}, \mathrm{~T}_{0}$ are the cpm in oocytes at time 0 (i.e., oocytes exposed to the solution for one sec), and $\mathrm{V}$ is the final oocyte volume (in $\mu \mathrm{l}$ ) after $10 \mathrm{~min}$ exposure to $1.3 \mathrm{M}$ ethylene glycol, which was estimated from the initial oocyte volume and the changes in volume under $1.3 \mathrm{M}$ ethylene glycol solution previously determined.

\section{Immunofluorescence microscopy and immunoblotting}

For immunohistochemistry, oocytes were fixed $4 \mathrm{~h}$ in 4\% paraformaldehyde in PBS (137 $\mathrm{mM} \mathrm{NaCl}, 2.7 \mathrm{mM}$ $\mathrm{KCl}, 100 \mathrm{mM} \mathrm{Na}_{2} \mathrm{HPO}_{4}, 2 \mathrm{mM} \mathrm{KH} \mathrm{PO}_{4}, \mathrm{pH}$ 7.4) and then washed, dehydrated and embedded in paraffin as described [73]. Sections of $7 \mu \mathrm{m}$ were then rehydrated and blocked in $5 \%$ goat serum, $0.1 \%$ BSA in PBST $(0.1 \%$ Tween in PBS). Incubation with a DrAqp3b rabbit affinity-purified antiserum (1:250) was performed overnight at $4{ }^{\circ} \mathrm{C}$ in $1 \%$ goat serum, $0.1 \%$ BSA in PBST. The antiserum was raised against a synthetic peptide corresponding to the $\mathrm{COOH}$ termini of DrAqp3b (CERLKLSAVSDKDAA) (Agrisera). After washing, sections were incubated with a secondary anti-rabbit IgG FITC-coupled antibody (Sigma) for $2 \mathrm{~h}$. Sections were mounted with fluoromount aqueous anti-fading medium (Sigma). Immunofluorescence was observed and documented with a Zeiss imager.z1 microscope.

For Western blotting, total and plasma membrane protein extracts were isolated from groups of 10 oocytes as described [74]. Protein samples were denaturated at $95^{\circ} \mathrm{C}$ in Laemmli sample buffer and the equivalent of 1 oocyte (in $15 \mu \mathrm{l}$ ) for total membrane, or 2 oocytes (in $30 \mu \mathrm{l})$ for plasma membrane, were deglycosylated by incubation with $500 \mathrm{U}$ of PNGase F (New England Biolabs Inc.) for $3 \mathrm{~h}$ at $37^{\circ} \mathrm{C}$. The enzyme was inactivated by $5 \mathrm{~min}$ incubation at $95^{\circ} \mathrm{C}$ before electrophoresis of the samples in a $12 \%$ SDS-PAGE. Proteins were blotted on Hybond ECL nitrocellulose membrane (Amersham Bioscience), and after blocking in 5\% nonfat dry milk in TBST (20 mM Tris, $140 \mathrm{mM} \mathrm{NaCl}, 0.1 \%$ Tween, $\mathrm{pH}$ 
7.6), membranes were incubated overnight at $4^{\circ} \mathrm{C}$ with anti-DrAqp3b antibody (1:500) diluted in blocking solution. Bound antibodies were detected with anti rabbit IgG antibody (1:2000) coupled to horseradish peroxidase (Rockland Inc.). Reactive protein bands were detected using Picomax sensitive chemiluminescent HRP substrate (Rockland Inc.).

\section{Statistics}

Data are expressed as mean \pm SEM. The data on oocyte water and solute permeability and ethylene glycol content are an average of 2-4 experiments each performed on a different batch of oocytes. Data was statistically analyzed by one-way ANOVA or by the unpaired Student's $t$ test; $p$ values $<0.05$ were considered significant.

\section{Additional material}

Additional file 1: Effect of $\mathrm{pH}$ on the permeability of control and DrAqp3b-expressing Xenopus laevis oocytes determined in solutions with diluted or undiluted ion concentrations. Osmotic water permeability $\left(P_{f} ; \mathrm{A}\right)$ and ethylene glycol permeability $\left(P_{E G} ; \mathrm{B}\right)$ of oocytes expressing $2 \mathrm{ng}$ cRNA of DrAqp3b at different pH. In A, oocytes were preincubated in normal MBS or in isotonic MBS containing $78 \mathrm{mM}$ $\mathrm{NaCl}$ and $20 \mathrm{mM}$ sucrose, and subsequently assayed for $P_{\mathrm{f}}$ using 10 times diluted MBS or a hyposmotic bathing solution made by removing the sucrose, respectively. The same values of $P_{\mathrm{f}}$ were obtained by using MBS containing $50 \mathrm{mM}$ or $25 \mathrm{mM} \mathrm{NaCl}$, and $56 \mathrm{mM}$ or $126 \mathrm{mM}$ sucrose, respectively (data not shown). In B, oocytes were preincubated with normal MBS or in isotonic MBS containing $38 \mathrm{mM} \mathrm{NaCl}$ and $100 \mathrm{mM}$ sucrose, prior to the swelling assays in isotonic MBS containing $100 \mathrm{mM}$ ethylene glycol. In both $A$ and $B$, values are the mean \pm SEM of a representative experiment ( $n=6$ oocytes).

Additional file 2: Functional characterization of additional DrAqp3b mutants in Xenopus laevis oocytes. Osmotic water permeability $\left(P_{f}\right)$ of oocytes expressing wild-type DrAqp3b (DrAqp3b-WT) or different DrAqp3b mutants at different $\mathrm{pH}$. Values are the mean \pm SEM of 2-3 experiments ( $n=8-10$ oocytes per construct). The asterisks indicate significant differences between DrAqp3b-WT and mutants at a given $\mathrm{pH}$ (Student's $t$ test, $p<0.05$ ).

Additional file 3: Forward and reverse primers employed to introduce mutations into the zebrafish Aqp3b cDNA. The table lists the oligonucleotide primers employed for the site-directed mutagenesis of the zebrafish Aqp3b cDNA.

\section{List of abbreviations}

AQP: aquaporin; GLP: aquaglyceroporin; $L_{\mathrm{p}}$ : hydraulic conductivity; $P_{f}$ : osmotic water permeability; $P_{\mathrm{s}}$ : solute permeability; $P_{\text {Gly: }}$ glycerol permeability; $P_{\mathrm{PG}}$ : propylene glycol permeability; $P_{\mathrm{EG}}$ : ethylene glycol permeability; $\sigma$ : reflection coefficient; MBS: modified Barth's medium; PNGase F: N-Glycosidase F; WT: wild-type.

\section{Acknowledgements}

This work was supported by grants from the Spanish Ministry of Education and Science (AGL2007-60262-AQUACYTE) and European Commission (MRTNCT-2006-035995-Aquaglyceroporins) to JC. FC was supported by a postdoctoral fellowship from Juan de la Cierva Program (Spanish Ministry of Education and Science). Participation of EL was financed by a travel grant from the Generalitat of Catalonia (2008PIV00035) for visiting professors.

\section{Author details}

'Laboratory of Institut de Recerca i Tecnologia Agroalimentàries (IRTA)Institut de Ciències del Mar, Consejo Superior de Investigaciones Científicas
(CSIC), 08003 Barcelona, Spain. ${ }^{2}$ Department of Marine Biology, Israel Oceanographic and Limnological Research, 81080 Haifa, Israel.

\section{Authors' contributions}

FC carried out the functional expression in oocytes, site-directed mutagenesis, swelling assays and cryoprotectant uptake experiments, and drafted the first version of the manuscript. FC and JC performed structural analyses and designed the mutant constructs. EL, together with $\mathrm{FC}$ and $\mathrm{JC}$ participated in the design of experiments and discussion of the results. JC conceived and coordinated the study, and together with EL wrote the final version of the manuscript. All authors read and approved the final manuscript.

Received: 11 October 2010 Accepted: 8 April 2011

Published: 8 April 2011

\section{References}

1. Fuller BJ, Lane N, Benson EE: Life in the Frozen State Boca raton: CRC Press LLC; 2004.

2. Fuller BJ, Paynter SJ: Cryopreservation of mammalian embryos. Methods Mol Biol 2007, 368:325-339.

3. Zhang T, Rawson DM, Pekarsky IB, Lubzens E: Low-temperature preservation of fish gonad cells and oocytes. In The Fish Oocyte: from Basic Studies to Biotechnological Applications. Edited by: Babin P, Cerdà J, Lubzens E. The Netherlands: Springer; 2007:411-436.

4. Songsasen N, Comizzoli P: A historical overview of embryo and oocyte preservation in the world of mammalian in vitro fertilization and biotechnology. In Preservation of Human Oocytes. Edited by: Coticchio G, Borini A. London: Informa Healthcare; 2009:1-11.

5. Benson $C T$, Critser JK: Variation of water permeability (Lp) and its activation energy (Ea) among unfertilized golden hamster and ICR murine oocytes. Cryobiology 1994, 31:215-223.

6. Mazur P: Principles of cryobiology. In Life in the Frozen State. Edited by: Fuller BJ, Lane N, Benson EE. Boca Raton: CRC Press LLC; 2004:3-66.

7. Pegg DE: Principles of cryopreservation. In Cryopreservation and FreezeDrying Protocols. Edited by: Day JG, Stacey GN. New York: Humana Press; 2007:39-57, [Walker JM (Series Editor) Methods in Molecular Biology, vol 368].

8. Fuller $B$, Paynter $S$ : The rational basis for controlled rate slow cooling. In Preservation of Human Oocytes. Edited by: Coticchio G, Borini A. London: Informa Healthcare; 2009:25-35.

9. Kuleshova LL: Fundamentals and current practice for vitrification. In Preservation of Human Oocytes. Edited by: Coticchio G, Borini A. London: Informa Healthcare; 2009:36-61.

10. Mazur P, Schneider U: Osmotic consequences of cryoprotectant permeability and its relation to the survival of frozen-thawed embryos. Theriogenology 1984, 21:68-79.

11. Fuller B, Paynter S: Fundamentals of cryobiology in reproductive medicine. Reprod Biomed Online 2004, 9:680-691.

12. Paynter SJ: A rational approach to oocyte cryopreservation. Reprod Biomed Online 2005, 10:578-586.

13. Bautista JA, Kanagawa H: Current status of vitrification of embryos and oocytes in domestic animals: ethylene glycol as an emerging cryoprotectant of choice. Jpn J Vet Res 1998, 45:183-191.

14. Liebermann J, Nawroth F, Isachenko V, Isachenko E, Rahimi G, Tucker MJ: Potential importance of vitrification in reproductive medicine. Biol Reprod 2002, 67:1671-1680.

15. Kasai M, Mukaida T: Cryopreservation of animal and human embryos by vitrification. Reprod Biomed Online 2004, 9:164-170.

16. De Santis L, Coticchio G, Paynter S, Albertini D, Hutt K, Cino I, laccarino M, Gambardella A, Flamigni C, Borini A: Permeability of human oocytes to ethylene glycol and their survival and spindle configurations after slow cooling cryopreservation. Hum Reprod 2007, 22:2776-2783.

17. Gautam SK, Verma V, Palta P, Chauhan MS, Manik RS: Effect of type of cryoprotectant on morphology and developmental competence of in vitro-matured buffalo (Bubalus bubalis) oocytes subjected to slow freezing or vitrification. Reprod Fertil Dev 2008, 20:490-496.

18. Sharma GT, Dubey PK, Chandra V: Morphological changes, DNA damage and developmental competence of in vitro matured, vitrified-thawed buffalo (Bubalus bubalis) oocytes: A comparative study of two cryoprotectants and two cryodevices. Cryobiology 2010, 60:315-321. 
19. Hagedorn M, Kleinhans FW, Freitas R, Liu J, Hsu EW, Wildt DE, Rall WF: Water distribution and permeability of zebrafish embryos, Brachydanio rerio. J Exp Zool 1997, 278:356-371.

20. Pedro PB, Yokoyama E, Zhu SE, Yoshida N, Valdez DM Jr, Tanaka M, Edashige K, Kasai M: Permeability of mouse oocytes and embryos at various developmental stages to five cryoprotectants. J Reprod Dev 2005, 51:235-246.

21. Valdez DM Jr, Miyamoto A, Hara T, Seki S, Kasai M, Edashige K: Water- and cryoprotectant-permeability of mature and immature oocytes in the medaka (Oryzias latipes). Cryobiology 2005, 50:93-102.

22. Seki S, Kouya T, Valdez DM Jr, Jin B, Hara T, Saida N, Kasai M, Edashige K: The permeability to water and cryoprotectants of immature and mature oocytes in the zebrafish (Danio rerio). Cryobiology 2007, 54:121-124.

23. Zhang T, Isayeva A, Adams SL, Rawson DM: Studies on membrane permeability of zebrafish (Danio rerio) oocytes in the presence of different cryoprotectants. Cryobiology 2005, 50:285-293.

24. Karlsson JO, Younis Al, Chan AW, Gould KG, Eroglu A: Permeability of the rhesus monkey oocyte membrane to water and common cryoprotectants. Mol Reprod Dev 2009, 76:321-333.

25. Cottichio G, Bonu MA: Cryopreservation and the cytoskeleton of the human oocyte. In Preservation of Human Oocytes. Edited by: Coticchio G, Borini A. London: Informa Healthcare; 2009:164-173.

26. King LS, Kozono D, Agre P: From structure to disease: the evolving tale of aquaporin biology. Nat Rev Mol Cell Biol 2004, 5:687-698

27. Litman T, Søgaard R, Zeuthen T: Ammonia and urea permeability of mammalian aquaporins. Handb Exp Pharmacol 2009, 190:327-358.

28. Tsukaguchi H, Shayakul C, Berger UV, Machenzie B, Devidas S, Guggino WB, van Hoek AN, Hediger MA: Molecular characterization of a broad selectivity neutral solute channel. J Biol Chem 1998, 273:24737-24743.

29. Tsukaguchi H, Weremowicz S, Morton CC, Hediger MA: Functional and molecular characterization of the human neutral solute channel aquaporin-9. Am J Physiol 1999, 277:F685-F696.

30. Meinild AK, Klaerke DA, Zeuthen T: Bidirectional water fluxes and specificity for small hydrophilic molecules in aquaporins 0-5. J Biol Chem 1998, 273:32446-32451

31. Yamaji Y, Valdez DM Jr, Seki S, Yazawa K, Urakawa C, Jin B, Kasai M, Kleinhans FW, Edashige K: Cryoprotectant permeability of aquaporin-3 expressed in Xenopus oocytes. Cryobiology 2006, 53:258-267.

32. Bhattacharjee $H$, Rosen BP, Mukhopadhyay R: Aquaglyceroporins and metalloid transport: implications in human diseases. Handb Exp Pharmacol 2009, 190:309-325.

33. Tanghe A, Van Dijck P, Dumortier F, Teunissen A, Hohmann S, Thevelein JM: Aquaporin expression corre-lates with freeze tolerance in baker's yeast and overexpression improves freeze tolerance in industrial strains. Appl Environ Microbiol 2002, 68:5981-5989.

34. Hagedorn M, Lance SL, Fonseca DM, Kleinhans FW, Artimov D, Fleischer R, Hoque ATMS, Hamilton MB, Pukazhenthi BS: Altering fish embryos with aquaporin-3: an essential step toward successful cryopreservation. Biol Reprod 2002, 67:961-966

35. Edashige K, Yamaji Y, Kleinhans FW, Kasai M: Artificial expression of aquaporin-3 improves the survival of mouse oocytes after cryopreservation. Biol Reprod 2003, 68:87-94.

36. Tanghe A, Van Dijck P, Colavizza D, Thevelein JM: Aquaporin-mediated improvement of freeze tolerance of Saccharomyces cerevisiae is restricted to rapid freezing conditions. Appl Environ Microbiol 2004, 70:3377-3382.

37. Edashige K, Kasai M: The movement of water and cryoprotectants in mammalian oocytes and embryos and its relevance to cryopreservation. J Mamm Ova Res 2007, 24:18-22.

38. Edashige K, Ohta S, Tanaka M, Kuwano T, Valdez DM Jr, Hara T, Jin B, Takahashi S, Seki S, Koshimoto C, Kasai M: The role of aquaporin 3 in the movement of water and cryoprotectants in mouse morulae. Biol Reprod 2007, 77:365-375.

39. Valdez DM Jr, Takao H, Miyamoto A, Seki S, Jin B, Kasai M, Edashige K: Expression of aquaporin-3 improves the permeability to water and cryoprotectants of immature oocytes in the medaka (Oryzias latipes). Cryobiology 2006, 53:160-168.

40. Seki S, Kouya T, Hara T, Valdez DM Jr, Jin B, Kasai M, Edashige K: Exogenous expression of rat aquaporin-3 enhances permeability to water and cryoprotectants of immature oocytes in the zebrafish (Danio rerio). J Reprod Dev 2007, 53:597-604.
41. Chauvigné F, Cerdà J: Expression of functional aquaporins in oocytes and embryos and the impact on cryopreservation. In Preservation of Human Oocytes. Edited by: Coticchio G, Borini A. London: Informa Healthcare; 2009:104-115.

42. Echevarría $M$, Windhager $E E$, Frindt $G$ : Selectivity of the renal collecting duct water channel aquaporin-3. J Biol Chem 1996, 271:25079-25082.

43. Yang B, Verkman AS: Water and glycerol permeabilities of aquaporins 1-5 and MIP determined quantitatively by expression of epitope-tagged constructs in Xenopus oocytes. J Biol Chem 1997, 272:16140-16146.

44. Zeuthen T, Klaerke DA: Transport of water and glycerol in aquaporin 3 is gated by $\mathrm{H}^{+}$. J Biol Chem 1999, 274:21631-21636.

45. Cabado AG, Alfonso A, Vieytes MR, Botana LM: Hypertonicity-induced intracellular pH changes in rat mast cells. Life Sci 2000, 67:1969-1982.

46. Xu X, Cui ZF, Wilkins RJ, Urban JP: Intracellular pH changes in isolated bovine articular chondrocytes during the loading and removal of cryoprotective agents. Cryobiology 2003, 46:161-173.

47. Pedersen SF, O'Donnell ME, Anderson SE, Cala PM: Physiology and pathophysiology of $\mathrm{Na}+/ \mathrm{H}+$ exchange and $\mathrm{Na}+-\mathrm{K}+-2 \mathrm{Cl}$ - cotransport in the heart, brain, and blood. Am J Physiol Regul Integr Comp Physiol 2006, 291:R1-R25.

48. Tingaud-Sequeira A, Calusinska M, Chauvigné F, Lozano J, Finn RN, Cerdà J: The zebrafish genome encodes the largest vertebrate repertoire of functional aquaporins with dual paralogy and substrate specificities similar to tetrapods. BMC Evol Biol 2010, 10:38.

49. Zelenina M, Bondar AA, Zelenin S, Aperia A: Nickel and extracellular acidification inhibit the water permeability of human aquaporin-3 in lung epithelial cells. J Biol Chem 2003, 278:30037-30043.

50. Németh-Cahalan KL, Hall JE: $\mathrm{pH}$ and calcium regulate the water permeability of aquaporin 0 . J Biol Chem 2000, 275:6777-6782.

51. Németh-Cahalan KL, Kalman K, Hall JE: Molecular basis of $\mathrm{pH}$ and $\mathrm{Ca}^{2+}$ regulation of aquaporin water permeability. J Gen Physiol 2004, 123:573-580.

52. Chen $H, W u$ Y, Voth $G A$ : Origins of proton transport behavior from selectivity domain mutations of the aquaporin-1 channel. Biophys J 2006, 90:L73-L75.

53. Fischer $\mathrm{M}$, Kaldenhoff $\mathrm{R}$ : On the $\mathrm{pH}$ regulation of plant aquaporins. J Biol Chem 2008, 283:33889-33892.

54. de Groot BL, Grubmüller H: Water permeation across biological membranes: mechanism and dynamics of aquaporin-1 and GlpF. Science 2001, 294:2353-2357.

55. Wu B, Beitz E: Aquaporins with selectivity for unconventional permeants. Cell Mol Life Sci 2007, 64:2413-2421.

56. Engel $A$, Fujiyoshi $Y$, Agre $P$ : The importance of aquaporin water channel protein structures. EMBO J 2000, 19:800-806

57. Yasui $\mathrm{M}: \mathrm{pH}$ regulated anion permeability of aquaporin-6. Handb Exp Pharmacol 2009, 190:299-308

58. Tingaud-Sequeira A, Zapater C, Chauvigné F, Otero D, Cerdà J: Adaptive plasticity of killifish (Fundulus heteroclitus) embryos: dehydrationstimulated development and differential aquaporin-3 expression. Am J Physiol Regul Integr Comp Physiol 2009, 296:R1041-R1052.

59. Maclver B, Cutler CP, Yin J, Hill MG, Zeidel ML, Hill WG: Expression and functional characterization of four aquaporin water channels from the European eel (Anguilla anguilla). J Exp Biol 2009, 212:2856-2863.

60. Sougrat $R$, Morand M, Gondran C, Barré $P$, Gobin R, Bonté F, Dumas M, Verbavatz JM: Functional expression of AQP3 in human skin epidermis and reconstructed epidermis. J Invest Dermatol 2002, 118:678-685.

61. Walz T, Fujiyoshi $Y$, Engel $A$ : The aquaporin structure and functional implications. Handb Exp Pharmacol 2009, 190:31-56.

62. Borini A, Coticchio G: The efficacy and safety of human oocyte cryopreservation by slow cooling. Semin Reprod Med 2009, 27:443-449.

63. Deen PM, Verdijk MA, Knoers NV, Wieringa $B$, Monnens $L A$, van Os $C H$, van Oost BA: Requirement of human renal water channel aquaporin-2 for vasopressin-dependent concentration of urine. Science 1994, 264:92-95.

64. National Center for Biotechnology Information (NCBI). [http://www.ncbi. nlm.nih.gov]

65. Higgins D, Thompson J, Gibson T, Thompson JD, Higgins DG, Gibson TJ: CLUSTAL W: improving the sensitivity of progressivemultiple sequence alignment through sequence weighting, position-specific gap penalties and weight matrix choice. Nucleic Acids Res 1994, 22:4673-4680.

66. Hall TA: BioEdit: a user-friendly biological sequence alignment editor and analysis program for Windows 95/98/N. Nucleic Acids Symp 1999, 41:95-98. 
67. Zampighi GA, Kreman M, Boorer KJ, Loo DDF, Bezanilla F, Chandy G, Hall JE, Wright EM: A method for determining the unitary functional capacity of cloned channels and transporters expressed in Xenopus laevis oocytes. J Membr Biol 1995, 148:65-78.

68. Verkman AS, Ives HE: Water permeability and fluidity of renal basolateral membranes. Am J Physiol 1986, 250:F633-F643.

69. Søgaard R, Zeuthen T: Test of blockers of AQP1 water permeability by a high-resolution method: no effects of tetraethylammonium ions or acetazolamide. Pflugers Arch 2008, 456:285-292.

70. MacGrath JJ, Hunter J, Bernard A, Fuller BJ: On the use of microdiffusion chamber methods to determine the coupled transport of water and cryoprotective agents across biological membranes. In Macroscopic and Microscopic Heat and Mass Transfer in Biomedical Engineering. Edited by: Diller KR, Shitzer A. Amsterdam: Elsevier Press; 1992:271-296.

71. Kedem O, Katchalsky A: Thermodynamic analysis of the permeability of biological membranes to non-electrolytes. Biochim Biophys Acta 1989, 1000:413-430.

72. Paynter SJ, Fuller BJ, Shaw RW: Temperature dependence of mature mouse oocyte membrane permeabilities in the presence of cryoprotectant. Cryobiology 1997, 34:122-130.

73. Tingaud-Sequeira A, Chauvigné F, Fabra M, Lozano J, Raldúa D, Cerdà J: Structural and functional divergence of two fish aquaporin-1 water channels following teleost-specific gene duplication. BMC Evol Biol 2008, 8:259.

74. Kamsteeg EJ, Deen PM: Detection of aquaporin-2 in the plasma membranes of oocytes: a novel isolation method with improved yield and purity. Biochem Biophys Res Commun 2001, 282:683-690.

doi:10.1186/1472-6750-11-34

Cite this article as: Chauvigné et al:: Design and characterization of genetically engineered zebrafish aquaporin-3 mutants highly permeable to the cryoprotectant ethylene glycol. BMC Biotechnology 2011 11:34.

\section{Submit your next manuscript to BioMed Central and take full advantage of:}

- Convenient online submission

- Thorough peer review

- No space constraints or color figure charges

- Immediate publication on acceptance

- Inclusion in PubMed, CAS, Scopus and Google Scholar

- Research which is freely available for redistribution

Submit your manuscript at www.biomedcentral.com/submit 